\title{
AG:DP/AFG/92/009
}

Terminal Report

\section{FIELD CROP PROTECTION IN NORTHERN} AFGHANISTAN

\section{AFGHANISTAN}

PROJECT FINDINGS AND RECOMMENDATIONS

UNITED NATIONS DEVELOPMENT PROGRAMME

FOOD AND AGRICULTURE ORGANIZATION OF THE UNITED NATIONS 


\title{
FIELD CROP PROTECTION IN NORTHERN AFGHANISTAN
}

\author{
AFGHANISTAN
}

\section{PROJECT FINDINGS AND RECOMMENDATIONS}

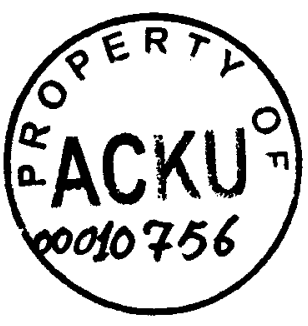

Report prepared for

the Government of Afghanistan

by

the Food and Agriculture Organization of the United Nations acting as executing agency for the United Nations Development Programme

UNITED NATIONS DEVELOPMENT PROGRAMME

FOOD AND AGRICULTURAL ORGANIZATION OF THE UNITED NATIONS

Rome, 1995 
The designations employed and the presentation of the material in this document do not imply the expression of any opinion whatsoever on the part of the. United Nations or the Food and Agriculture Organization of the United Nations concerning the legal status of any country, territory, city or area or of its authorities, or concerning the delimitation of its frontiers or boundaries. 
The Food and Agriculture Organization is greatly indebted to all those who assisted in the implementation of the project by providing information, advice, facilities and hospitality and is especially grateful to the senior and assistant technical staff who carried out the project activities. In particular, gratitude is extended to the Afghan national staff for their courage and dedication, local government officials in the provinces of Afghanistan, participating NGOs, ODA, NRI, CABI and IIBC for technical assistance, GTZ for chemical analysis of the pesticide samples and WFP for organizing the transportation of inputs to remote and improbable locations. 
1.1 Background to the project 1

1.1.1 Plant protection and the civil war

1.1.2 Wheat production in northern Afghanistan

1.1.3 Plant pests and diseases of wheat in northern Afghanistan 2

1.1.4 Plant protection activities prior to the project

1.1.5 The current state of the plant protection organizations

1.2 Outline of official arrangements 3

1.3 Objectives of the project 4

2. RESULTS AND CONCLUSIONS 5

2.1 Farmer training and the extension network 5

2.1 .1 Input sale scheme $\quad 6$

2.1.2 Farmer Certification scheme 8

2.1.3 Socio-economic study of the community-based extension network 8

2.1.4 Relations between the PPQD, extensionists and farmers 10

2.1.5 NGO participation in plant protection activities 10

$\begin{array}{lll}2.2 & \text { The locust and sunnpest monitoring system } & 11\end{array}$

2.2.1 Locusts in northern Afghanistan 11

2.2.2 Characteristics of the locust outbreaks $\quad 12$

2.2.3 Sunnpest in northern Afghanistan 12

2.2.4 Characteristics of the sunnpest outbreak 14

2.2.5 Crop Protection Information System (CPIS) 16

2.3 Options for control methods of locust and sunnpest 19

2.4 Major plant pests of other important crops identified and prioritized 20

$\begin{array}{lll}2.5 & \text { Training } & 20\end{array}$

$\begin{array}{lll}2.6 & \text { Pesticides } & 20\end{array}$ 
2.6.1 Benzene hexachloride (BHC) 21

$\begin{array}{ll}\text { 2.6.2 Other pesticides and application equipment } & \cdot 23\end{array}$

$\begin{array}{lll}2.7 & \text { Sub-projects carried out under AFG/92/009 }\end{array}$

2.7.1 Desert Locust Project UNO/AFG/021/UNA 24

2.7.2. UNO/AFG/022/UNA and UNO/AFG/024/UNA

3. RECOMMENDATIONS 25

$\begin{array}{lll}3.1 & \text { Introduction } & 25\end{array}$

3.2 The crop extension network and the farmer certification scheme 25

$\begin{array}{ll}3.3 & \text { The sale of inputs } \\ 3.4 & 25\end{array}$

$\begin{array}{lll}3.4 & \text { Socio-economic impact studies of project activities } & 26\end{array}$

3.5 Crop Protection Information System 26

$\begin{array}{ll}3.6 & \text { Control methods } \\ \end{array}$

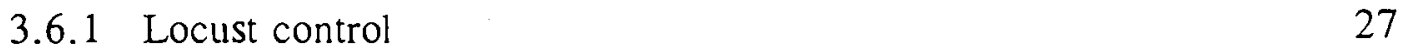

$\begin{array}{ll}3.6 .2 \text { Sunnpest control } & 27\end{array}$

$\begin{array}{lll}3.7 & \text { The future role of the PPQD } & 27\end{array}$

3.7.1 Sub-contracting the PPQD 28

$\begin{array}{ll}3.7 .2 & \text { Privatization of the input delivery } \\ 3.7 .3 & 28\end{array}$

3.7.3 Visits and staff exchange within Afghanistan 28

3.7.4 Facilitation of bilateral and multilateral links within south and central Asia 28

3.8 Identification of needs and supply of plant protection resources 29

$\begin{array}{lll}3.9 & \text { Study tours } & 29\end{array}$

3.9.1 Secondment of PPQD officer(s) to Iran 29

3.9.2 Entomology/IIBC tour to Pakistan 30

3.9.3 Farmer Field School study tours $\quad 30$

$\begin{array}{lll}3.10 & \text { Pesticides } & 30\end{array}$

3.10.1 BHC strategies 31 
$\begin{array}{lll}\text { Appendix } 1 & \text { Project staff } & 33\end{array}$

Appendix $2 \quad$ Study tours and training conducted under the project 34

$\begin{array}{llll}\text { Appendix } 3 & \text { Inventory of project equipment } & 35\end{array}$

Appendix $4 \quad$ Table of activities funded by the proceeds from the sale of inputs 36

$\begin{array}{lll}\text { Appendix } 5 & \text { An example of the certificate used to certify farmers } & 37\end{array}$

$\begin{array}{lll}\text { Appendix } 6 & \text { Training activities } & 40\end{array}$

$\begin{array}{lll}\text { Appendix } 7 \mathrm{a} & \text { Locusts in northern Afghanistan - characteristics and control } & 42\end{array}$

Appendix 7b Review of information on locusts as wheat pests in Afghanistan 45

$\begin{array}{lll}\text { Appendix } 8 & \text { Sunnpest in northern Afghanistan } & 50\end{array}$

$\begin{array}{lll}\text { Appendix } 9 & \text { Other pest problems } & 57\end{array}$

Appendix 10 Chemical container specifications for use in farmer-based control operations

$\begin{array}{lll}\text { Appendix } 11 & \text { BHC in northern Afghanistan } & 62\end{array}$

$\begin{array}{lll}\text { Appendix } 12 & \text { Field documents } & 63\end{array}$

$\begin{array}{lll}\text { Appendix } 13 & \text { References } & 64\end{array}$

\section{LIST OF FIGURES}

Figure 1 Areas covered by project

xii

Figure 2 Organogram of implementation model used for the community extensionist training

Figure 3 Chemical sale and farmer certification scheme

Figure 4

Locust areas in northern Afghanistan

Figure 5

Sunnpest distribution in northern Afghanistan, 1990-94

Figure 6

Weather stations

Figure 7 BHC stocks in northern Afghanistan 
viii 


\section{LIST OF ABBREVIATIONS}

AFC

$\mathrm{BBC}$

$\mathrm{BHC}$

CABI

$\mathrm{CE}$

CIMMYT

CIS

CPIS

CSA

CTA

DSA

ECLO

FAO

FCP

GIS

ICARDA

ICP

IGR

IIBC

IL

IPM
Afghan Fertilizer Company

British Broadcasting Corporation

Benzene hexachloride

Commonwealth Agricultural Bureaux International (Oxon, UK)

Crop Extensionist

International Centre for Maize and Wheat Inprovement

Commonwealth of Independent States

Crop Protection Information System

Contractual Service Agreement (contract between FAO and the Implementing Partner)

Chief Technical Adviser

Daily subsistence allowance

Emergency Centre for Locust Operations (FAO)

Food and Agriculture Organization of the United Nations

Field Crop Protection Project (AFG/92/009)

Geographic Information System (FAO)

International Centre for Agricultural Research in the Dry Areas

Integrated Crop Production project (AFG/94/002)

Insect Growth Regulators

International Institute for Biological Control

Italian Locust

Integrated Pest Management 
Ministry of Agriculture and Irrigation (previously the Ministry of Agriculture and Land Reform)

ML

Moroccan Locust

NAC

Norwegian Afghanistan Committee

NGO

Non-Governmental Organization

NPPP

National Plant Protection Programme

NRI

Natural Resources Institute (UK)

ODA

Overseas Development Administration (UK)

OXFAM

Oxford Famine Relief (UK-based international NGO)

PPQD

Plant Protection and Quarantine Department of the MAI

PRA

Participatory Rural Appraisal

SCA

Swedish Committee for Afghanistan

SP

Sunnpest

ST

Supervisor Trainer

ULV

Ultra-Low Volume

UNDP

United Nations Development Programme

UNOCA

Original acronym for UNOCHA

UNOCHA

United Nations Office for Coordination of Humanitarian Assistance for Afghanistan

USAID

Agency for International Development

WFP

World Food Programme 


\section{SUMMARY}

In the spring of 1990, outbreaks of sunnpest and locusts occurred in the major wheat-growing areas of northern Afghanistan. The farmers in rural areas had no means to protect their wheat, and major crop losses occurred in many areas. An emergency response was mounted by the United Nations, implemented through NGOs with technical and logistical support from FAO. The emergency response evolved through several phases; the final phase ended in the spring of 1993. A major finding of the activities was that it was the inability of the local farming communities to mount an appropriate response that emphasized the seriousness of the pest outbreaks. Catering for each "emergency" as it arose was not addressing the farmers' need for sustainable plant protection, neither with regard to the control of such outbreaks nor with regard to the chronic pest problems occurring in most cropping seasons. It also failed to address the need for more environmentally-acceptable alternatives.

Valuable lessons were learnt from the emergency activities. They formed the basis of the Field Crop Protection Project AFG/92/009 (FCP). The objective of the FCP was to secure wheat production in northern Afghanistan against losses caused by plague insects. This was accomplished through a range of activities based around farmer training and the linking of inputs to the training by means of a sale scheme. The principal behind pest control was one of individual farmer crop protection, rather than a widespread public service "campaign" against the entire insect pest population. Over 8000 farmers were trained under the scheme. Extension material was provided to assist in farmer training; on-farm trials demonstrated the relative advantages of different wheat varieties; the initiation of a pest-monitoring programme improved the information available to the local plant protection services and community trainers; and strategies to rid the country of obsolete stockpiles of pesticides were initiated. A Crop Protection Information System (CPIS) was developed as a management tool to tie together many of the project's diverse activities by providing a framework to capture the information generated. The CPIS also provides the basic structure for the pest-monitoring system initiated by the project. A study tour was conducted, which aimed to give regional plant protection officers some insight into the regional plant protection activities in Iran (where similar pest problems are encountered).

The project consolidated the efforts of three seasons of emergency activities and successfully demonstrated that it is possible to provide plant protection assistance to farmers, in conditions of minimum infrastructure, in a way that forms the basis for longer-term sustainable and integrated activities. It has become widely known to the farming communities of northern Afghanistan and provides the focus for the annual crop protection activities. 


\section{SUMMARY OF RECOMMENDATIONS}

Overall, the project found that it is possible to deliver plant protection assistance in a way that will contribute, in the long term, to farmers taking responsibility for their own plant protection activities. The process established - of using community and NGO extensionists and the provincial Plant Protection and Quarantine Department (PPQD) as trainers - is effective and does not require expensive infrastructure. Under this approach, the emphasis is on human resources, beginning with farmers. It is therefore recommended that these activities be continued in the plant protection component of the Integrated Crop Production project. However, it is recognized that these activities are not sustainable and more support needs to be given to the training and advisory role of the provincial PPQD and NGOs. Increased emphasis is recommended in the area of extensionist training through farmer field schools.

It is stressed that insecticides are not an appropriate response to plant pest and disease emergencies, unless supported by an integrated farmer-training system and an equitable process of providing access to inputs. The results of the project indicate that inputs should be priced in some way and that they be linked to a training and extension programme. It is recommended that the input sale scheme be continued, with the aim of phasing out all subsidies for insecticides over the next five years. Socio-economic studies will have to be continued as a means of improving the process of farmer training and project monitoring.

Refer to Figure 1 for the areas covered by the project. 
Figure 1.

FAO FIELD CROP PROTECTION PROJECT: AFG/92/009

Operational districts for Northern/Western/Central regions

Period: January 1994 - March 1995

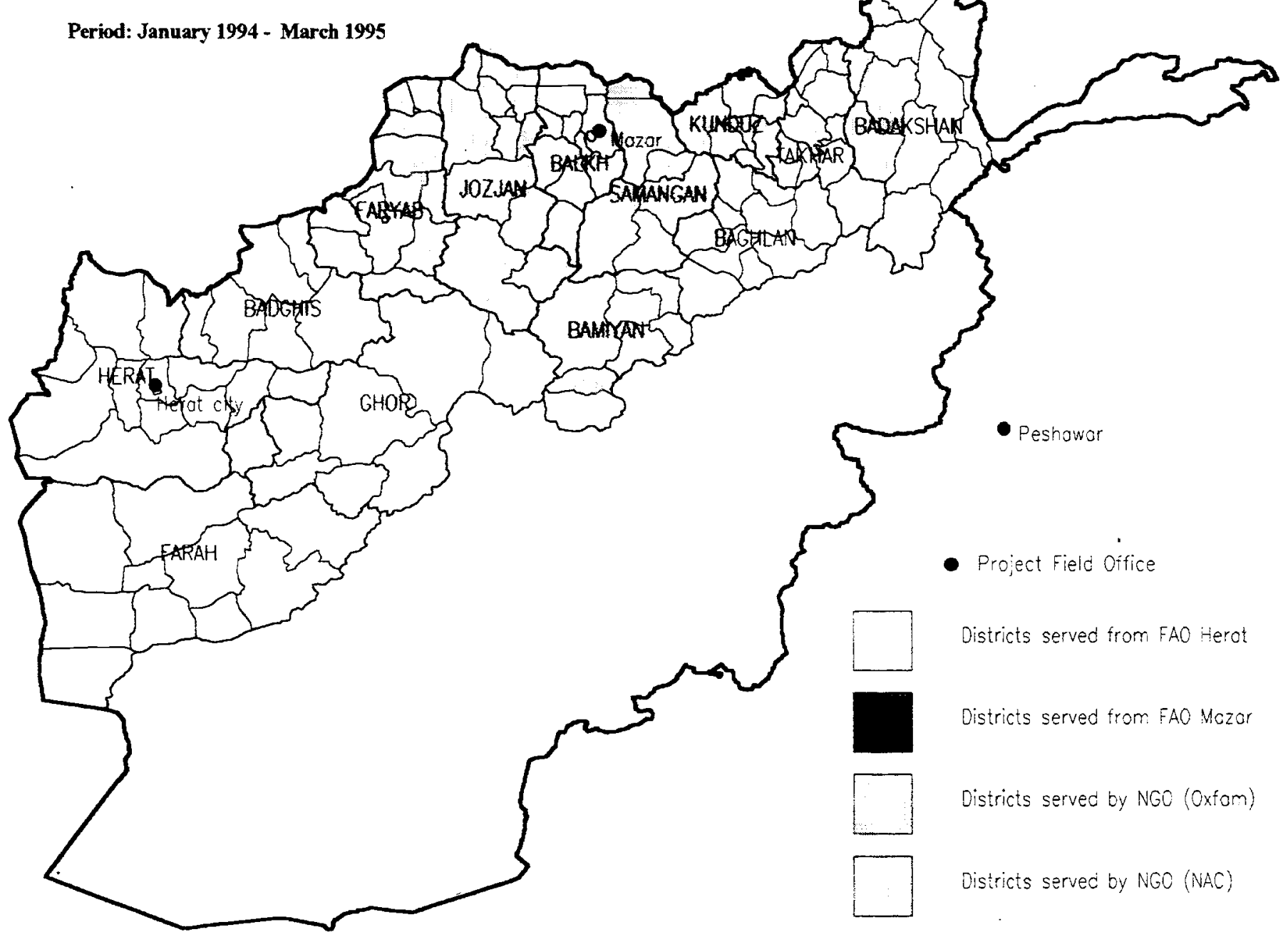

xii 
$x i v$ 


\section{INTRODUCTION}

\subsection{BACKGROUND TO THE PROJECT}

\subsubsection{Plant protection and the civil war}

Afghanistan is, and has been for the past 17 years, a country involved in a civil war. For those wheat farmers who have not been driven from their land, the practical effects of the war on their day-to-day farming life has been indirect. The reason that they continued to grow wheat throughout the war was that the vast majority of them were used to dealing with most production problems without outside help. However, in 1990, acute outbreaks of locusts and sunnpest rendered their isolation complete. The disruption caused to the agrarian system by the war was blamed for the pest outbreak, although there was no direct evidence to support this assumption. In the absence of information it was not possible to discern the actual level of the pest infestations and thus to gauge the appropriate response.

The United Nations intervened to assist farmers in preventing major crop losses, on the assumption that it was more efficient to provide chemicals and sprayers than food aid: if farmers could protect their own crops, this would lead to increased stability and food security in rural areas, which in turn would have a positive effect on refugee return. The aim was to cover as wide an area as possible in the affected areas of northern Afghanistan by training farmers and supplying chemicals.

Difficulties arose from the fact that the rural areas affected by the pests were divided (both politically and militarily) from the major provincial towns. The majority of the rural areas came under what was known as "Mujahadeen" control. Communities were controlled by disparate armed groups commanded by local war lords ("Commanders"). These groups directly opposed the central government and aligned themselves with the various opposition parties based, at the time, in Peshawar in Pakistan. As a consequence of this situation, a cadre of trainers, known as "Supervisors", was formed with UN assistance, from NGO Afghan staff in Peshawar in Pakistan. After training, they crossed the Hindu Kush to reach northern Afghanistan, and undertook the training of farmers in rural areas in the north. FAO provided logistical and technical support to this training as well as supplying the inputs from the provincial capitals in the north. What became known to the United Nations as "cross line missions" were staged from the government-controlled, provincial centres to the oppositioncontrolled, rural areas, as the NGO trainers and community extensionists recruited by them were unable to travel to the government towns. In April 1992, the central government fell to the Mujahadeen forces. However, the country remained divided during the project, as factions fought for control throughout Afghanistan.

\subsubsection{Wheat production in northern Afghanistan}

Northern Afghanistan has a semi-arid continental climate, with cold winters, reliable winter and spring rains (November to March), and long hot dry summers and autumns. For over eight months of the year no rain falls. Cropping takes place between the altitudes of $300 \mathrm{~m}$ (on the low steppe) and $3500 \mathrm{~m}$. Northern Afghanistan is the breadbasket of the country, accounting for 70 percent of food grain production, comprised mainly of wheat. Before the war, it was a food-exporting region; its wheat crop plays a critical part in determining the level of the country's food deficit. The cereal crop of northern Afghanistan is also socially important in that it is at the basis of the way of life in rural areas. Cropping strategies are fundamentally not based on economic maximization, but are governed by individual farmers' 
efforts at personal well-being and survival. In land-utilization terms, this means that every effort is made to keep the food resources from falling under someone else's control. ${ }^{1}$ Of the total agricultural area of approximately 2.5 million ha (i.e. $12 \%$ of land area - rough grazing steppes not included), less than half is irrigated. All provinces grow wheat, legumes and vegetables. Cotton, maize and sugar beets are grown in most provinces. Kunduz, Baghlan and Takhar also grow rice. On irrigated farmland in the river valleys, wheat, barley, maize, rice, cotton, oilseeds, alfalfa, vegetables, fruit trees and grapes are grown, as well as poplars for lumber production. Wheat yields on irrigated land vary from 800 to $2400 \mathrm{~kg} / \mathrm{ha}$.

Village inhabitants also farm extensive rainfed areas. The typical rainfed cropping pattern consists of a rotation cycle of one year cereals and the second year fallow, or linseed, sesame or melons. Wheat is sown either in the autumn or in spring. Harvest is from midJune to late July, depending on the time of sowing and elevation. Without access to a source of improved seed, the area relies on local, late-maturing varieties of wheat. No fertilizer is used in the rainfed areas. The other cereal planted is barley, which is used exclusively as fodder. Melons and oilseed crops are sown in May. Rainfed yields of wheat vary from 350 to $1000 \mathrm{~kg} / \mathrm{ha}$. Farming is not mechanized on any large scale and oxen are used as draft animals with wooden ploughs. Harvesting is generally by hand.

\subsubsection{Plant pests and diseases of wheat in northern Afghanistan}

The most serious of the pests of wheat are locusts and sunnpest. The Moroccan Locust (ML) and to a lesser extent the Italian Locust (IL) - Dociostaurus maroccanus and Calliptamus italicus, respectively - are a permanent potential threat to crops, particularly to cereals in the rainfed areas ("lalmi"). They breed in the range land steppes ("dasht"). In addition, a complex of sunnpest species or "stink bug" (Eurygaster, Dolycoris, Carpocoris, Aelia and other genera ), which aestivates and overwinters in the mountains, invades grain fields in the spring. Rainfed wheat is particularly afflicted by sunnpest. Appendix 8 reviews the reported outbreaks of sunnpest in Afghanistan. Considerable reductions in wheat yields also occur in wet years due to outbreaks of diseases, notably rust (Puccinia sp.) and smut (Ustilago sp.).

\subsubsection{Plant protection activities prior to the project}

Before the war, extensive locust control programmes were conducted annually by the Plant Protection and Quarantine Department (PPQD) in cooperation with, and supported by, the then Soviet Union. Treating the dasht of Balkh, Samangan, Kunduz and Jozjan provinces with benzene hexachloride (BHC) dust, applied by motorized sprayers mounted on trucks, was an annual event in the north. These activities took place almost irrespective of the actual infestation levels of ML. The ex-USSR had assisted with locust control in the north in this way for over two decades. Sunnpest control was undertaken sporadically. Records show that there was an outbreak of sunnpest in the Miamana area of Faryab in 1957, which caused a yield loss of at least 40 percent. However, the problem seems to have remained intermittent and there are no systematic records of control operations being conducted. For further information refer to Appendix 8, which gives a breakdown on the records that are available for sunnpest outbreaks in Afghanistan. 
In August 1990, UNO/AFG/006/UNA commenced the provision of emergency assistance to the northern provinces for locust and sunnpest control. The emergency response was extended over three cropping seasons and finished at the end of 1993. Funding was provided through the United Nations Office for Coordination of Humanitarian Assistance for Afghanistan (UNOCHA). Over 150000 ha of crops were sprayed during this period; indeed; this is believed to be one of the largest ground crop protection exercises undertaken anywhere using hand-held ULV sprayers. The activities of the Field Crop Protection Project AFG/92/009 developed the approach and refined the implementation procedures commenced in these earlier projects.

\subsubsection{The current state of the plant protection organizations}

In the northern provinces, no formally-recognized plant protection strategy exists, although there are PPQD offices in the provincial offices of the Ministry of Agriculture and Irrigation (MAI) in Herat, Badghis, Faryab, Jozjan, Sarepul, Balkh, Samangan and Baghlan. Only nominal representations exist in Badghis and Farah provinces. The provincial offices are largely without resources and many staff have not been paid for several months. At the time of writing, regional PPQD offices have no functioning association with the central PPQD in Kabul. Inter-regional cooperation and communication is not common. Regional offices usually have neither technical records nor training resources. The central records and offices of the PPQD in Kabul have reportedly been destroyed. Most staff are remnants of the prewar MAI, or Ministry of Agriculture and Land Reform (as it was known during the 1980s). There is apparently no new recruitment and there is a tendency for older staff to want to give priority to reinstating the system as it was before the war. In a traditional defence against an infestation as widespread as the 1990 reports indicate, control operations would have been organized, implemented and funded by the state. However, given that Afghanistan is divided by war and the state of the PPQD, it would have been difficult to implement the project only through the PPQD. This, together with an increasing acceptance of the disadvantage of control strategies based on the large-scale application of pesticides, leads to the initial strategy of farmers being trained directly to protect their own crops. In spite of its problems, it must however be emphasized that the PPQD can assist with farmer training and monitoring and there have been notable individual contributions from many provincial PPQD staff.

The parastatal Afghan Fertilizer Company (AFC) handled the sale of chemicals and sprayers before the war. The AFC still exists in the provinces of Balkh and Herat, but the offices are effectively inoperative and appear to have a poor working relationship with the provincial PPQD. The AFC was in the past responsible for the commercial importation of pesticides and its sale to farmers. The PPQD would provide farmers with a prescription for whatever ailed their crop and the AFC would provide the pesticide, functioning in much the same way as a chemist shop. Pesticides were heavily subsidized under this system and there was no training of farmers.

\subsection{OUTLINE OF OFFICIAL ARRANGEMENTS}

The Project Document was signed by UNDP on 12 December 1993, by FAO on 12 December 1993 and by the Government on 11 December 1993. The project was scheduled to last 12 months with a UNDP budget of US\$1 008220 . There was no counterpart contribution. FAO was designated as the executing agency. There was no designated 
counterpart agency, however the Plant Protection and Quarantine Department of the Ministry of Agriculture and Land Reform assisted with the implementation of a range of project activities in the regions where it functioned. The project became operational. on 1 January 1994. Project field offices were established in Mazar and Herat. An administrative and support office was kept in Islamabad. As a result of the need to carry over activities into the next cropping season, the project was extended by three months. The total UNDP contribution remained at US\$1 008220 , and the project terminated on 31 March 1995.

\subsection{OBJECTIVES OF THE PROJECT}

The project's development objective, as stated in the project document, was to "to secure wheat production in northern Afghanistan against losses caused by plague insects".

The project had the following immediate objectives, as stated in the project document:

i) To establish a community training and extension network in target districts in conjunction with a sustainable means of providing advice and inputs.

ii) To provide the basis for an effective and efficient system of monitoring, early warning and control of Moroccan Locust (and other locust species involved) and sunnpest.

iii) To provide the community crop extensionists with adequate extension material to conduct the training of farmers.

iv) To offer short-term strategies that address the problem of obsolete and dangerous chemicals.

The results of the project are discussed in the context of the above objectives in the following chapter. 


\section{RESULTS AND CONCLUSIONS}

\subsection{FARMER TRAINING AND THE EXTENSION NETWORK}

The primary objective of the training programme was "to establish a community training and extension network in target districts in conjunction with a sustainable means of providing advice and inputs".

Over 8000 farmers received training under the project during the spring (pre-season) and autumn (post-season) training sessions during 1994 and the spring of 1995. The primary training was in the use of the ultra-low volume (ULV) sprayer, ${ }^{1}$ the safe handling of ULV pesticides and the damaging effect they can have on the environment if not used correctly and judiciously. While the focus of the training was on chemical control, pest ecology was also explained in relation to how it effects pest outbreaks. Farmers were trained by communitynominated extensionists or PPQD staff, who were trained at FAO training courses in the provincial centres. Many of these people had been with the previous emergency programme for three years. They were under the supervision of an area supervisor, known as a "Supervisor Trainer" (ST), who also monitored activities. The community supervisors had also participated in the emergency project and most had received their initial training in Peshawar in 1990. All extensionists were recruited directly by the FAO project, or through an NGO, for three months, to undertake training in their areas during the pest season. Postseason debriefing sessions were held with all extensionists in June and July. Additional refresher training sessions were held in the autumn. PPQD staff were also involved in project activities and participated in these training sessions, both as trainees and resource staff.

The project successfully set up a network of trainers with access to chemicals and equipment, in such a way that no farmer in northern Afghanistan was more than one day from assistance in the event of an outbreak. The principal benefit derived from this aspect of the work was that, in conditions of minimum infrastructure, farmers themselves are capable of conducting their own crop protection, albeit with the support of inputs from outside agencies.

The system has limitations however. Using community trainers on such a scale tends to spread resources thinly and it is difficult to provide ongoing technical support throughout the season. More face-to-face and regular contact is required at all levels: between farmers, community extensionists, PPQD regional officers, and FAO trainers and monitors. Due to the short growing season and the extensive area over which farmers were trained, the course curriculum tended to be fairly limited and of insufficient length. As a result, too much emphasis was placed on the use of chemical control techniques, which can be taught readily in a few days, at the expense of a more integrated, ecological approach to pest management. Pest ecology training requires more time and resources and is best demonstrated practically during the cropping season.

A further element of the training of the crop extension network was the use of the $\mathrm{BBC}$ Dari language service for Afghanistan. The BBC was used to transmit public service

1

Ultra-Low Volume spraying refers to the use of concentrated chemicals, that do not require mixing with water, being dispensed through spray equipment specially designed to spray fine and uniform droplets. ULV chemicals are oil based to prevent the droplets evaporating. ULV spraying relies on wind to disperse the chemicals and has the advantage that large areas can be treated relatively quickly. 
announcements relating to the timing of training courses. In addition to invitation letters and field liaison missions, this proved to be a successful way of informing the farming communities of the activities of the project and is evidence that the increased use of local and international radio and TV services for training purposes should be pursued in the future.

Figure 2 describes the relationship between the various participating implementers which give rise to the entity referred to as the "crop extension network". See also Appendix 6 for the figures concerning the number of people trained and the type of training.

\subsubsection{Input sale scheme}

In 1991 and 1992, the emergency predecessor projects distributed chemicals and equipment free of charge. It became apparent that the free distribution of inputs caused several problems:

i) The distribution of free pesticides encouraged their overuse, with all the attendant environmental and health risks.

ii) Chemicals are hoarded, smuggled, misdirected to where they are not required, or they enter the black market.

iii) There is no indication of the actual demand for the chemicals, since they are not factored as a cost of production.

iv) The role of the PPQD, as an organization that carries out free spraying, was perpetuated.

v) As there was no state control throughout the project area, it was virtually impossible to monitor pesticide use.

As the basis of the programme was to encourage farmers to protect their own crops, it was decided to provide inputs to the farmers at a subsidized cost. It was found that some of the above problems were overcome, however, the high level of subsidies and the current economic status of the majority of farmers in the rainfed wheat-producing areas meant that many also remain. The selling of inputs also generated funds that could be used to support the operations of the PPQD and to purchase additional inputs.

Chemicals and sprayers were sold through the sale scheme described in Figure 3. The proceeds from the sales were placed in provincial bank accounts. The operation of the bank account was covered by a memorandum of agreement with the regional MAI, and the project and the funds were used to purchase such things as motorbikes and fuel as well as to fund operational costs and repairs to buildings. In addition, $50 \mathrm{t}$ of sulphur were purchased locally using these funds, and this is being sold through the input sale scheme.

Overall, the system is moving towards a sustainable process of delivering chemicals and sprayers linked to training, while at the same time providing benefits for the regional PPQD. It also provides a mechanism for introducing IPM techniques. If managed correctly, and subsidy levels continue to be reduced, the unwarranted use of chemicals should be discouraged. 


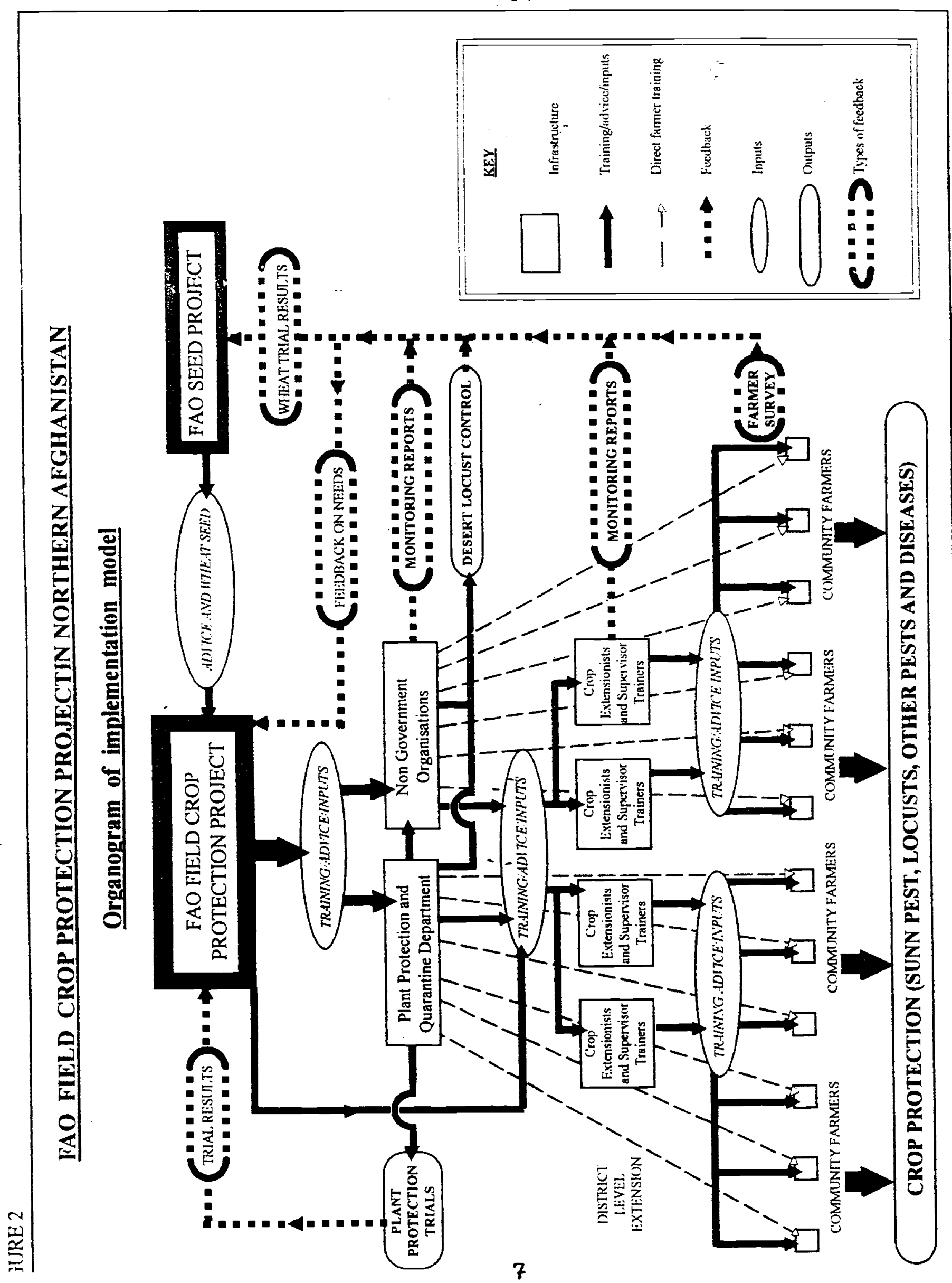




\subsubsection{Farmer certification scheme}

In an effort to link training to chemical inputs, a farmer certification scheme was initiated as a part of the training programme (Figure 3). To obtain access to chemicals, farmers had to be certified by a bon a fide FAO-accredited trainer (see Appendix 5 for an example of the certificate used). It is recognized that the certification scheme may emphasize chemical control. However, there is the advantage that controls can be placed on the distribution of chemicals. The reduction of subsidies should also contribute to a reduction in the emphasis on chemicals. The certification scheme requires further refinement over the coming two seasons.

\subsubsection{Socio-economic study of the community-based extension network}

As part of the primary objective of the project, it was proposed that a socio-economic aspect to the work be introduced to monitor the effectiveness of activities and provide an indication of how the community-based training network could be improved or changed.

The international NGO, Oxfam, was engaged to put together a team to carry out an assessment of the work in one project area (Faryab Province). This study was unique in that an NGO was monitoring a United Nations programme. This had the advantage of providing an independent assessment of all structures - including government - in one area. The results were produced in a report, "Socio-Economic Assessment of Faryab Province", Oxfam (1995), which is provided as an attachment to the Terminal Report. The socio-economic study indicates in detail some of the impacts of the project's activities and provides a picture of rural life in a selected project area. It also provides information on a range of socioeconomic and agricultural indicators, an assessment of the agricultural infrastructure and options for developing agricultural assistance to the area, and as such is a useful reference for future work in the area.

In the opinion of many of those farmers interviewed, the project has had a positive impact. It is concluded that the project's approach of using community extensionists was successful as a vehicle for reaching farmers with more up-to-date training, though there is a need to increase the range of services provided. It is recognized that this system is not selfsustaining. The report also concludes that the community-based crop extensionists and the provincial PPQD staff require extensive retraining, and that $\mathrm{PPQD}$ staff be more fully involved in the farmer-training process. The study also highlighted the specific need for highresolution information on which to base decisions, if the community participation process is to be successful. The collection of such information is clearly not a simple task; furthermore, one of the intrinsic results of the study would appear to be how little is currently known and how much institutional memory was lost during the war. The recommendation to establish an NGO to work directly in the area with nascent local structures could be read as an indication that the PPQD would find it difficult to embrace the more recent implementation strategies of the UN. Taking into account the PPQD's circumstances, without direct support it is clearly unrealistic to expect that they should be able to carry out the community participation activities of the current and upcoming project work. In this regard, there would appear to be scope for the further involvement of the PPQD in information collection and monitoring at district level. 
Figure 3 . Input sale and certification scheme

\section{Integrated plant protection training and certification scheme for farmers}

To be able to purchase insecticides farmers must first be trained. If they successfully complete the training they will receive a certificate allowing them to apply to purchase chemicals.

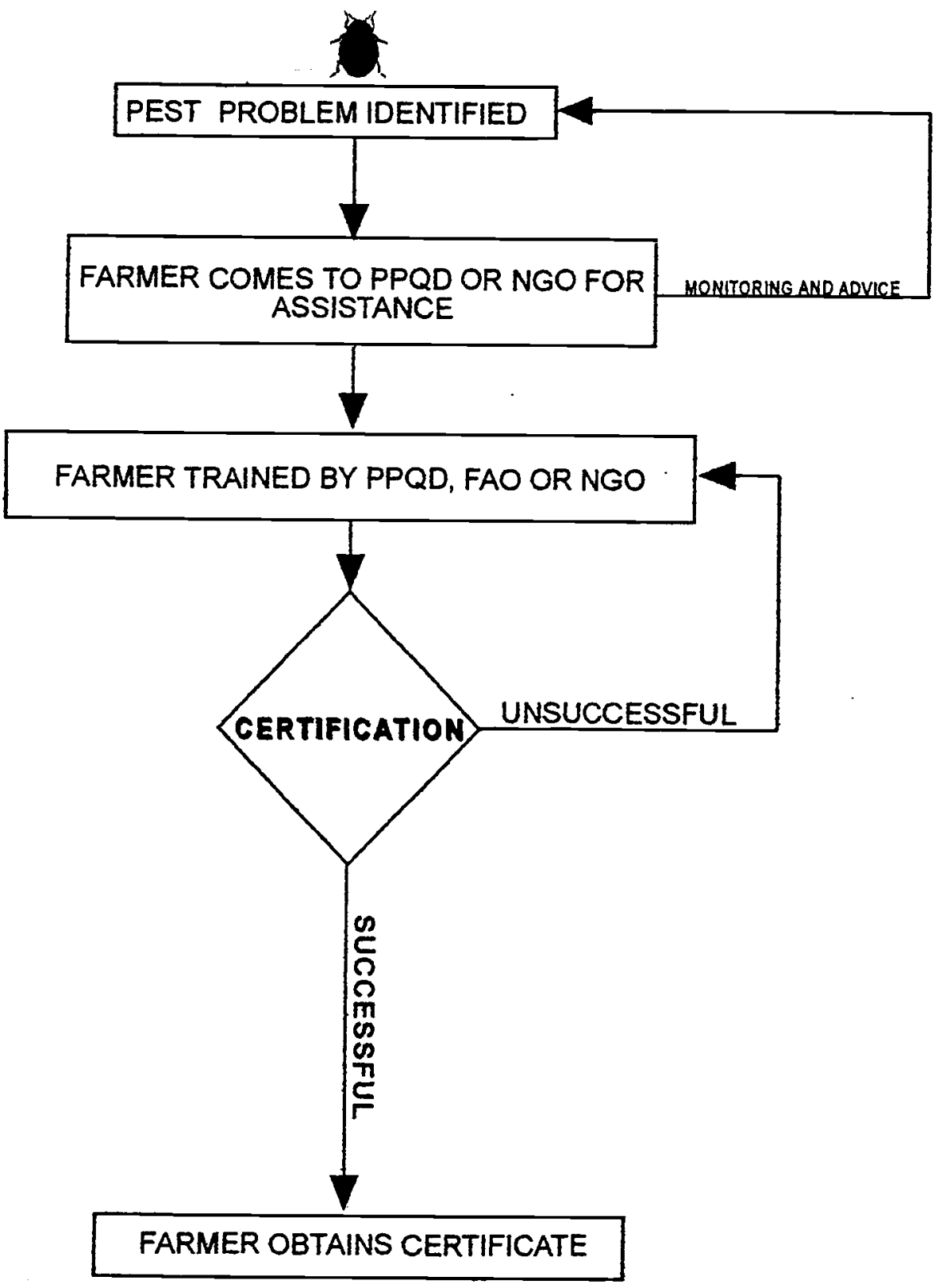

ONCE CERTIFIED THE FARMER CAN THEN APPLY TO PURCHASE CHEMICALS AND EQUIPMENT. ONLY SUCCESSFULLY TRAINED AND CERTIFIED FARMERS CAN APPLY TO PURCHASE CHEMICALS. HE FIRST PAYS THE MONEY INTO THE DESIGNATED BANK ACCOUNT.

HE THEN TAKES DEPOSIT SLIP AS PROOF OF PAYMENT BACK TO THE AGENT RELEASING CHEMICAL. the RELEASING AGent CHECKS he is CERTIFIEd AND RELEASES ChEMICAL. 


\subsubsection{Relations between the PPQD, extensionists and farmers}

In general, officials from both the central PPQD of the MAI and the provincial PPQD expressed reservations about the effectiveness of community-based trainers (Crop Extensionists - CE) and NGO extensionists. The perception that farmers are unable to make crop production management decisions or utilize crop production inputs effectively also appeared to be widely held. FAO project staff were thus at times criticized for directing resources towards NGOs, community-based extensionists or farmers directly, instead of through the PPQD. These observations should be seen in the context of a very poorlyresourced PPQD; however, the shortage of resources notwithstanding, there would appear to be a tendency in the PPQD to "privatize information" or selectively withhold information to support their position. Without the incentives provided by the project, it is believed that little emphasis would have been placed on training and that extension methods would have continued to be prescriptive, with little to no dialogue developed with farmers.

The long-term sustainability of the community trainers is doubtful once the support of the project is withdrawn, unless they can be supported by the community they serve. This may have some precedent in communities, as the appointing of individuals with responsibility for communal activities would appear to be common practice. For instance, in most villages there is an "Amir Ab", a water bailiff who apportions irrigation water on behalf of the community. Individual crop extensionists are already responsible for organizing the community when the common problem of locusts or sunnpest arises, and they act as an intermediary between the community and the technical and material resources provided by the project. The link has been critical to the extension process and its continuation in some form is seen as being pivotal for the future development of farmer-based plant protection activities. The careful selection of crop extensionists will also be an important factor in their future effectiveness. The military commanders in each area often appointed people to carry out this role in the past; more satisfactory, however, are other cases in which extensionists have been respected educated farmers or ex-NGO staff from Peshawar.

The project has also tried to marry the community-nominated extensionists with the local PPQD, by emphasizing the training and advisory role of PPQD officers at the seasonal training courses. However the feelings of farmers and CEs towards PPQD officers have been mixed. An often-expressed complaint was that PPQD staff did nothing to help the farmers in the past and very few communities had been visited by a PPQD officer in recent years. Consequently, farmers often expect very little from PPQD officers. While there were notable individual exceptions, there appears to be a lack of communication between the PPQD and the communities they are expected to serve. This will create difficulties for the project in the future unless some means of improving the relationship is found. Further consideration of these relationships can be found in the FAO/Oxfam socio-economic study.

\subsubsection{NGO participation in plant protection activities}

Two NGOs were engaged on Contractual Service Agreements (CSA) to carry out training and monitor the distribution of the allocated inputs in areas remote from the main centres. Oxfam carried out work in Bamyan Province of central Afghanistan, and the Norwegian Afghanistan Committee (NAC) worked in two districts of Badakshan (see Figure 1).

The NGOs were able to successfully deliver low-level training to farmers. No locusts were reported in the NAC area and the training of farmers was successfully carried out. Oxfam supported farmer-training and crop protection activities in one district of Bamyan 
where an outbreak of various species of local grasshoppers threatened wheat crops. Timely action by Oxfam reportedly prevented crop losses.

The use of CSA with NGOs will, it is believed, be most successful when the NGO has an established presence; in the case outlined above, both NGOs had previously established agricultural assistance programmes in their respective areas. However they did not have a specialized plant protection component in their agricultural assistance programme, nor did they employ plant protection specialists. Thus, while the NGO provided an avenue for introducing plant protection assistance, they are often unable to provide a consistent level of technical support for their extensionists. The strength of NGOs will to a large extent depend on their ability to include plant protection training in their agricultural programmes. The lack of longer-term technical support, which the NGOs can usually provide, restricts their usefulness, at present, in tactical interventions. This problem will have to be addressed in the longer-term project, as will the more general question of the long-term sustainability of NGO activities. Coordination between the various facets of the upcoming ICP project should allow a range of assistance (plant protection, improved seed, horticulture, agronomy) to be focused through individual NGOs, thus improving the technical support provided by the NGO.

\subsection{THE LOCUST AND SUNNPEST MONITORING SYSTEM}

A further objective of the project was to "provide the basis for an effective system of monitoring, early warning and control of Moroccan Locust (and other grasshopper species) and sunnpest".

The monitoring system that has been developed centres around what has been termed a "Crop Protection Information System" (CPIS). Information from the various monitoring aspects of the plant protection project is processed through this system, described below in para. 2.2.5.

\subsubsection{Locusts in northern Afghanistan}

During 1994, 2200 ha in northern Afghanistan were sprayed with ULV hand sprayers against Moroccan Locust infestations. Refer to Figure 4 for the areas where ML infestations were sprayed. Hoppers of ML attacked irrigated wheat in Shindand District of Herat Province. The project assisted the Herat PPQD staff to train farmers and distribute chemicals and sprayers. Gregarious ${ }^{1}$ laying of Moroccan Locust was observed in Balkh Province and it is anticipated that this may lead to the development of hopper bands in April 1995, which will require control operations with the support of FAO. However, successful hatching could be restricted, given the high levels of parasitism in the egg beds located. Across the border, in Uzbekistan, it has been reported that 130000 ha contain extensive egg beds and the authorities there expect a major outbreak. The area of southern Tajikistan is also of concern, as no control was undertaken due to poor security. Low numbers of IL and endemic

\footnotetext{
1

"Gregarious" refers to a general observation regarding the behaviour of locusts. Locusts are not always in large numbers. However when they behave gregariously, swarms form, massive and dense egg beds can be laid, and immature locusts can form in densities of over $5000 / \mathrm{m}^{2}$. This, together with their migratory behaviour, is what distinguishes a locust from a grasshopper.
} 
grasshoppers contributed to marginal losses throughout the project area. This population would appear to represent the normal background numbers present in years of population recession. For further details, refer to the recommendations on control strategies in Appendix 7.

\subsubsection{Characteristics of the locust outbreaks}

Over the last four years, the outbreaks of ML manifested themselves, not as a widespread "plague", but as localized outbreaks. The ML in central Asia has only one generation a year, i.e. it hatches from eggs in the ground of the dasht in spring (around the beginning of April at the lower altitudes), spends from three to five weeks as an immature "hopper" without wings, fledges (gains its wings) and then migrates to feed in suitable vegetation and oviposit (lay eggs). Crops are threatened when locusts are in the immature phase and during the initial migration to feed. The hatching and growth of the ML coincides with the ripening of the annual wheat crop. Around June-July in northern Afghanistan, adults may form gregarious groups (swarms) and lay eggs. In northern Afghanistan, the ML spends over eight months in the ground as an egg (over 80 percent of its entire life span). Parasites in the egg stage can significantly reduce the number which eventually hatch. The eggs then remain in the ground until next spring, when the cycle begins again.

Given this life cycle, they are, in theory, a relatively manageable and predictable problem. Laying swarms can be observed and egg beds located and monitored for levels of parasitism. It is important that the monitoring of parasite levels be pursued, since this may provide an indicator of future population trends. Attempts have been made in the past to dig up egg-pod beds as a control measure, or to use egg-pod surveys as a technique for forecasting locust populations. However, the huge areas in northern Afghanistan where egg laying may occur would preclude either activity being undertaken successfully.

Refer to Figure 4 for Moroccan Locust outbreak areas in northern Afghanistan. For further details, refer to Appendix 7.

\subsubsection{Sunnpest in northern Afghanistan}

Sunnpest (SP) outbreaks occurred in the districts of Ghulran and Kushk in Herat Province and in pockets in the northern province of Jozjan. In all cases, trained community extensionists and PPQD officers supported by the FAO project were able to provide assistance and prevent crop losses. Elsewhere in the north there were few insect problems reported. Densities reached more than 100 sunnpest $/ \mathrm{m}^{2}$ (mixed species). A total of 20600 ha were sprayed against sunnpest infestations in northern and western Afghanistan in 1994. The majority of the spraying was in Herat Province. Chemical consumption was 12934 litres. 
Figure 4.

Areas offected by Moroccon locust - $\bigcirc$

(Itolion loucst distribution soid

to be identical)

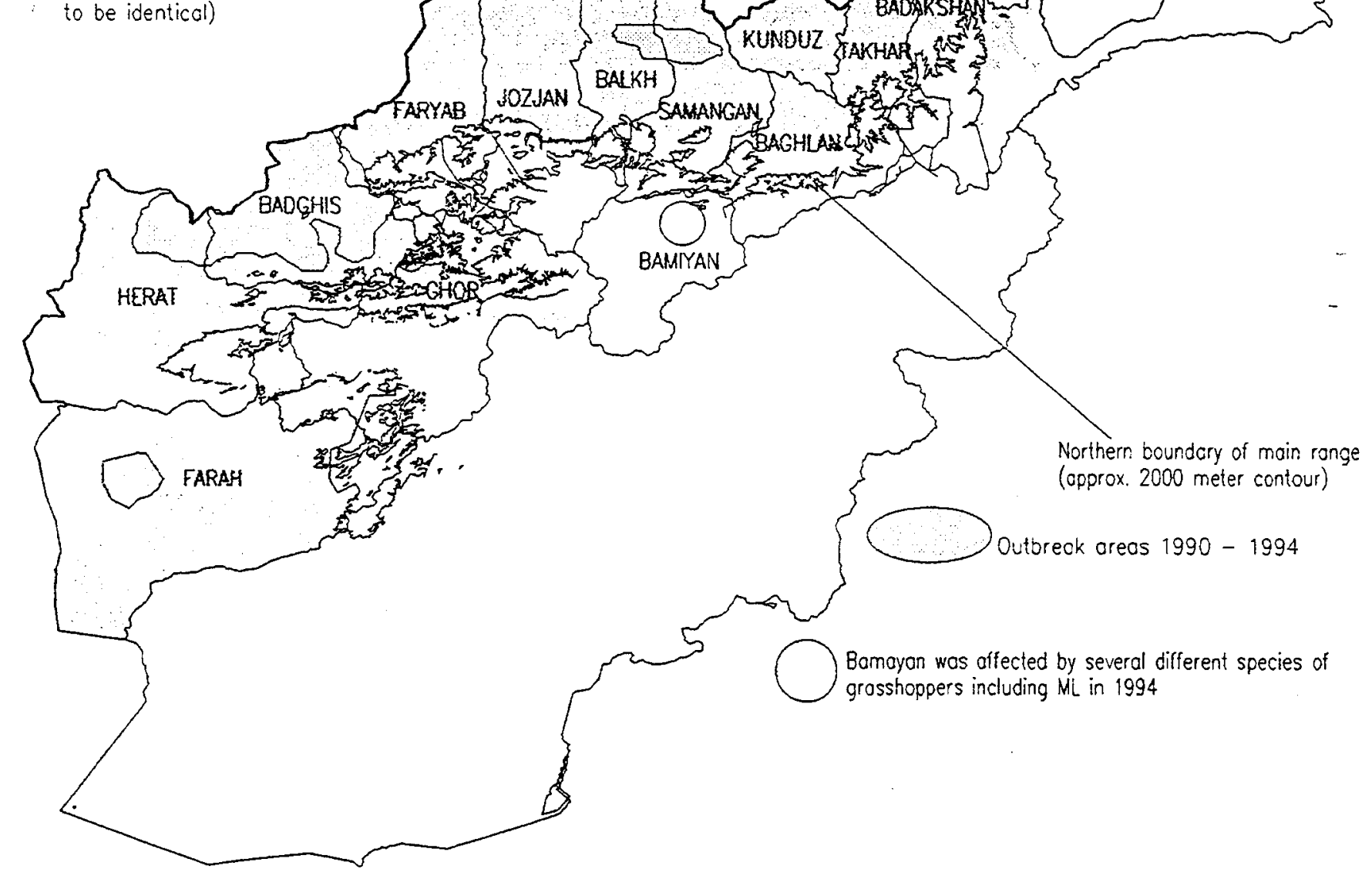




\subsubsection{Characteristics of the sunnpest outbreak}

The outbreak of sunnpest in 1990 was attributed to factors caused by the war, including: changing farming practices, lack of manpower and the degradation of wheat varieties. There is circumstantial evidence to suggest that disruption to farming practices and the spread of rainfed farming into previously uncultivated areas of favourable sunnpest habitat can cause outbreaks (ICARDA/FAO Conference on Sunnpest, Syria). While these factors may have played a part, it is more likely that the sunnpest were always present and various environmental factors contributed to an outbreak that overwhelmed a farming community suffering from the depredations, not of insects, but of war. A complex of four species of sunnpest (genera Dolycoris, Eurygaster, Carpocoris and Aelia) have been recorded in Afghanistan (Brown, Donskaff et al.). However there appears to have been no systematic monitoring of their populations and their apparent sudden arrival on the scene in the context of the war precipitated the declaration of an emergency. Whether this was generally justifiable or not is arguable, but there is no doubt that crops were being lost and rural communities were suffering. Though outbreaks such as those that occurred in 1990 and 1994 are acute and localized rather than widespread, overall they still represent a major perennial cause of production losses. Refer to Appendix 8 for details on sunnpest in northern Afghanistan and see Figure 5 for the distribution of sunnpest 1994 from project records, and the distribution encountered between 1990 and 1994.

Many questions regarding sunnpest in Afghanistan remain unanswered. Are the populations linked to breeding in Iran, Turkmenistan and Uzbekistan? How do changing landuse, cropping practices and wheat varieties influence sunnpest infestations? Can trap crops provide some protection? Answers to these questions and others will be important to developing longer-term control strategies, and efforts need to be made to improve understanding.

Further fundamental questions also remain regarding crop losses. What is the actual quantifiable damage to a wheat crop and how much damage can be tolerated? What is the relative importance of the various species of SP found in Afghanistan? Do all species cause similar damage to wheat, including a reduction in baking quality? Can damage be related to sunnpest densities? Should attempts be made to establish action thresholds, as has been done in other countries in the region? Economic damage to the crop can occur at densities as low as two adults $/ \mathrm{m}^{2}$, according to the Iranian plant protection authorities. In Afghanistan no economic threshold of density has been set. There are good reasons not to set a threshold level, because it tends to encourage prescriptive and palliative spraying. Spraying when a threshold density occurs fails to take into account the presence of predators and parasites as well as the stage of the insect in relation to the stage of the crop. These questions are considered in more detail in Appendix 8. 
Figure 5 .

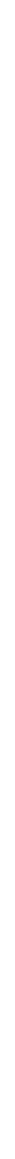




\subsubsection{Crop Protection Information System (CPIS)}

In the current circumstances in Afghanistan, it is difficult to obtain objective information regarding insect problems. There is a heavy reliance on farmer reports and other indirect indicators. The PPQD has no systematic record of pest outbreaks as they were reportedly destroyed or lost in Kabul. While this is an unsatisfactory basis for planning, it should not prevent plant protection activities from being undertaken. In recent years, the acute outbreak of pests, without apparent warning, has been a commonly repeated pattern in northern Afghanistan. In the absence of a better understanding of the situation, there is a risk of starting a cycle of only providing a short-term emergency response to what is most probably a longer-term, recurrent pest problem. One way of moving away from an emergency reaction is to improve the information available for making decisions.

Over the preceding four years, the UN-assisted plant protection activities generated ever-increasing amounts of information and data in the form of questionnaires, spray records and crop-monitoring reports. Other information is buried in mission reports and literature. However, while the information accumulated, there was no mechanism for capturing and processing it in a form that was immediately useful. There is little point in collecting information if there is no means of accessing, presenting and transferring it back to field activities. To this end, the FCP has initiated the development of what has been termed a Crop Protection Information System (CPIS).

The Crop Protection Information System provides a framework to capture the various data and information generated within the project and from outside sources (such as pest reports). This includes information collected by crop monitors and other survey data. Thus it is a management tool for presenting a diverse range of information, as well as systematically recording data relevant to pest occurrences. The CPIS also aims to provide a framework that can be adopted by the Afghan Government at some stage. Other sources of information in addition to the CPIS include: remote-sensing data collected by FAO on Afghanistan and the database being developed by the FAO IPM project in the Philippines.

For further information on the CPIS, refer to Dobson's report (Dobson, 1993 Appendix 13), which outlines its structure and relevant reporting forms.

The main activities generating information for the CPIS are:

i) On-farm trials of early-maturing rainfed wheat varieties: Manipulation of wheat variety and the timing of planting may reduce crop losses from sunnpest by interrupting the coincidence of the vulnerable stage of the wheat and attack by the pests. In the autumn of 1994, the project established a series of on-farm variety trials as a start to testing this hypothesis. A further aim of the trials is to provide standard control crops for monitoring purposes in areas that are subject to invasion by. sunnpest. These are described in more detail in the section discussing control options (para. 2.3). The results of these trials will not be available until the end of the 1995 cropping season and hence do not fall within the current reporting period.

See Appendix 8 for more information on the wheat trials that have been established.

ii) Annual surveys of overwintering sumnest adults: Surveys of overwintering adult sunnest populations were carried out in Herat and Miamana during 1994. The systematic surveying of overwintering populations at fixed monitoring sites should provide an indicator of the relative abundance of the pest from one year to the next (Watt, Brown et al.). As part of a sunnpest monitoring system, these surveys have to be conducted routinely every spring. The results of the current work will become 
apparent under the forthcoming Integrated Crop Production Project (AFG/94/002). Refer to Appendix 8 for more details.

iii) Spring locust surveys on fixed transect routes/late summer surveys for laying swarms: Standard locust survey techniques are to be employed on fixed transect routes. These will provide an indicator of relative abundance from one year to the next. Refer to the CPIS report by Dobson (Dobson, 1994 - Appendix 12) for information on standard locust survey forms that are to be used.

iv) Farmer questionnaires: Subjective information collected before, during and after the season is collated by extensionists in the form of a farmer questionnaire. This provides a range of information on farming systems, social and economic indicators, spray activities and crop yields. Refer to Dobson's report (Dobson, 1994 Appendix 12) for more information on the structure of the questionnaires.

v) Weather monitoring: Afghanistan has no functioning weather stations that can provide information relevant to the growing of wheat in the northern area. The project established a system of weather monitoring stations in the project area to provide basic agroclimatic information. This information will be linked to other monitoring information through the CPIS. Refer to Figure 6 for the location of basic weather stations set up by the project.

For more information on the CPIS, refer to the report by Dobson (Dec. 1994). 
Figure 6.

Sites of meteorological stations in regions covered by the FAO Crop Protection Project

Source: Climwat and FAO

11 Dec 94

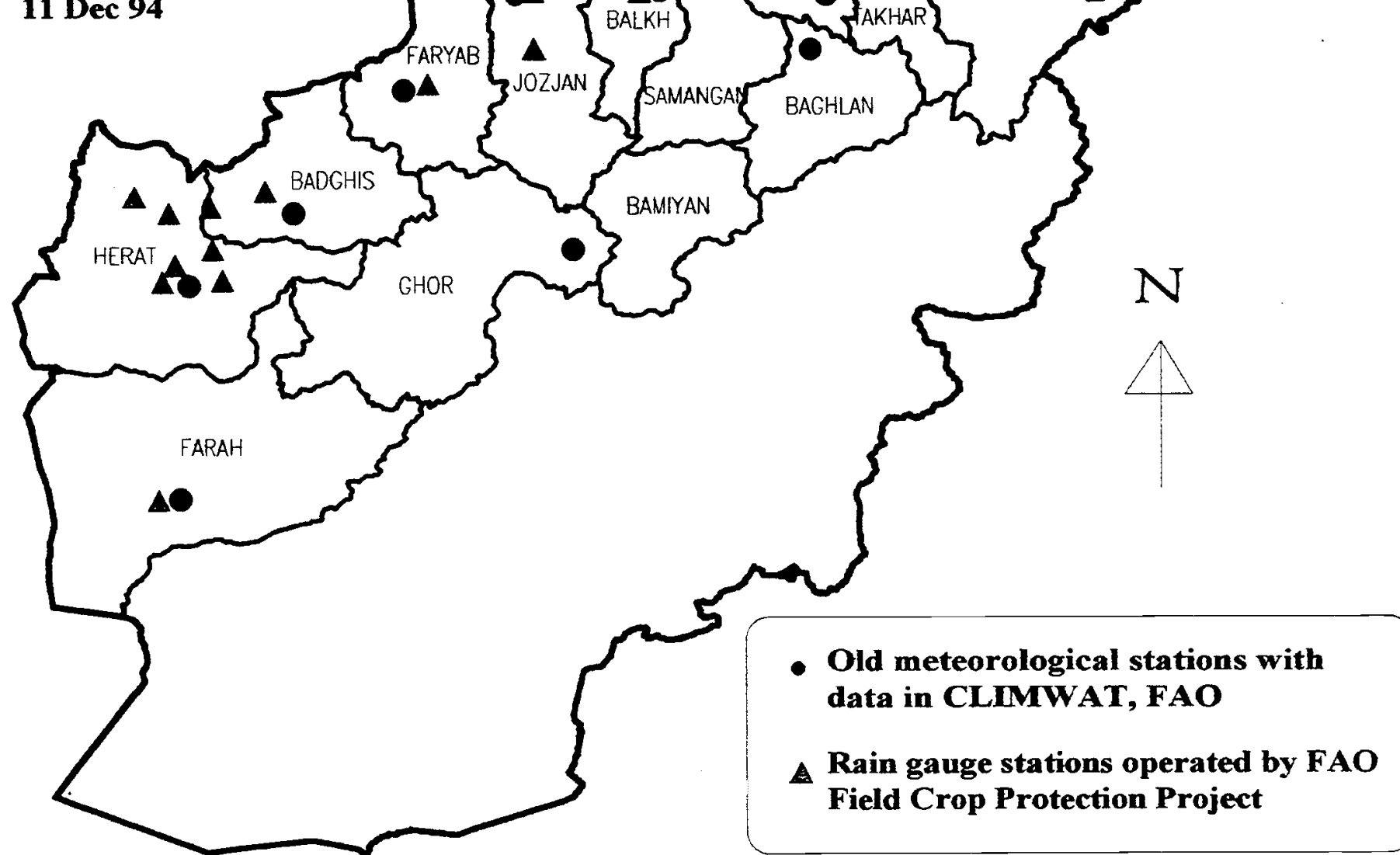




\subsection{OPTIONS FOR CONTROL METHODS OF LOCUST AND SUNNPEST}

One objective of the project was to provide the basis for effective and efficient control of sunnpest and locusts. There are various viable technical options for controlling these pests. These are discussed in Appendix 7 for locusts and Appendix 8 for sunnpest. Appendix 10 gives technical details and application rates of the chemicals used in the project.

In summary, the project has concluded that the following options exist:

i) Do nothing: A conscious or unconscious decision to do nothing must always be considered. A farmer will make an "unconscious" decision when he is unaware of the seriousness of the pest problem or of the availability of control options. He may make . a conscious decision if he is aware of the technical, environmental and economic implications of alternative options or if the inputs required are unavailable. In any event, the choice to do nothing will often be the best one, as in many cases the pest problem will take care of itself through natural factors. However, such a decision is difficult for farmers to take and for PPQD staff to recommend, particularly where free or subsidized inputs are available. It may also be politically difficult, as the MAI will be under pressure to "do something" when confronted with a pest.

ii) Use non-chemical control methods: This is the basis of current "integrated" pest management practices and is clearly an attractive option from an environmental, ecological and economic standpoint. Unfortunately, as sunnpest and locusts are both migratory "outbreak" pests, non-chemical control alternatives are limited and chemical control will have to be employed in most cases. Nevertheless, the possible utilization of such methods, particularly for sunnpest control, must continue to be explored. In an integrated approach for these pests, a range of non-chemical alternatives can be adopted alongside pesticides. These are discussed in more detail in Appendixes 7 and 8.

iii) Chemical control by farmers: The main thrust of the project's activities has been that of enabling farmers to make realistic decisions about the need to control pests attacking their own crop and, if necessary, to apply appropriate control measures to protect their crops. This system does not rely on a large, functioning government infrastructure. Overall, this approach has been found to be successful for SP in particular, and in many cases for ML and IL. It is recognized, however, that locusts breeding away from cropping areas may have to be controlled on a limited "campaign" basis. Refer to Appendix 7 for more details.

iv) Chemical control through large-scale "campaigns": Such campaigns, conducted by governments as a public service, were the basis of pre-war locust control strategies in northern Afghanistan. However, there now appears to be a general understanding of the technical, environmental and economic disadvantages of such strategies, and it is hoped that every attempt will be made to avoid their re-adoption in Afghanistan. 


\subsection{MAJOR PLANT PESTS OF OTHER IMPORTANT CROPS IDENTIFIED AND PRIORITIZED}

Project activities included an assessment of pest problems in crops other than wheat and the preparation of recommendations for control strategies. In undertaking this, the project has identified a number of regional pest problems:

- $\quad$ that appear to be key pests in economically important crops;

- that are of apparent concern to farmers;

for which there is a likelihood of developing and implementing a successful pest management strategy at farmer level.

These are described in Appendix 9, but there remains an immediate need to undertake more detailed pest and disease survey activities in order to reach a better understanding of the problems involved.

\subsection{Traning}

Community crop extensionists and PPQD trainers were provided with extension material to carry out farmer training. The material was in the form of a manual that provided information necessary for the training of farmers. The English version of the manual is submitted as an attachment to this report. The training manual developed by the project was aimed at providing trainers with resource material, in addition to being a guide to the training of farmers. It also provides a valuable record of available information on wheat pests in northern Afghanistan and their control. The project also employed and utilized a wide range of other training materials, including labelled collections of key pests and examples of crop damage, $35 \mathrm{~mm}$ slides and overhead projectors. See Appendix 6 for further details on the crop extensionist training programme.

\subsection{PESTICIDES}

One of the key findings of the emergency project was that the crop protection input distribution process should avoid creating an artificial demand for pesticides. There has been relatively little recent use of pesticides in Afghanistan compared with other countries in the region. However, in the past, the chemicals were used indiscriminantly, with the resulting accumulation of stockpiles of obsolete and dangerous chemicals, which cause disposal and environmental problems. An objective of the FCP was to offer short-term strategies to address this issue.

Pesticides that have passed their expiry date, chemicals packed in inadequate containers and those that are banned elsewhere in the world on environmental or public health grounds are a problem in many countries, including Afghanistan. There are several reasons for the accumulation of such chemicals: lack of government control (though legislation exists to prevent their importation); centralized decision-making, leading to large quantities being given as aid, which is not linked to the actual demand within the country; the absence of the means to distribute and properly use the chemicals once they arrive in the country; poor warehousing and unsuitable packaging. Government subsidies have also played a role, resulting in a distortion of the demand for chemicals and encouraging their overuse. Chemicals given as aid have a similar affect on government subsidization. All these factors have been at work in Afghanistan; as a result, there are stockpiles of chemicals that are 
causing environmental and public health problems, as well impeding the-introduction of more appropriate pest management practices.

\subsubsection{Benzene hexachloride (BHC)}

The project carried out an inventory of all. BHC dust in northern Afghanistan: it was found that there are $5820 \mathrm{t}$ of $\mathrm{BHC}$ in stockpiles in northern Afghanistan; there are no reported stockpiles elsewhere in the country (see Figure 7 for the distribution of BHC stocks in the north of Afghanistan). For further information see Appendix 11. BHC was given as aid from the former Soviet Union and has been applied in Afghanistan for locust control for over 20 years. BHC is not used for sunnpest control. The larger stockpiles indicated in Figure 7 are now administered by the provincial authorities, and in some cases they represent the only input resource at the disposal of the PPQD.

The presence of such large quantities of BHC, the fact that everyone in the PPQD has been inculcated in its use, almost as a palliative, for locust control and the fact that it is virtually free, results in it being applied indiscriminantly. Not only does this have adverse environmental and public health effects, it also acts as a disincentive for the adoption of more appropriate pest management practices. 


\subsubsection{Other pesticides and application equipment}

In addition to the substantial stocks of BHC, smaller amounts of other expired pesticides are stored in various locations in northern Afghanistan. Most of these are the remnants of the stocks previously held by the AFC and the PPQD. They include both toxic organophosphates and mercurial seed dressings. They are in many cases stored in containers that are too large for farmer use without decanting; many are damaged, leaking and otherwise deteriorated. Labels are frequently missing and rarely written in Dari or Farsi.

In the future, every effort must be made to avoid the accumulation of unwanted, unsuitable, expired pesticides, and the project, for its part, has attempted to address this problem by considering the following:

i) Procurement policies and procedures: In order to overcome the problem of accumulating chemicals, some of the principles of a "just-in-time" delivery system need to be applied to the procurement of chemicals, whether for replenishment of strategic stocks or for an emergency outbreak. The more timely delivery of chemicals as a realistic option will vary according to the circumstances, and with the benefit of hindsight, the principles of closer delivery scheduling of smaller consignments of chemicals could have been applied in Afghanistan. AGPP (FAO) has conducted some work on the delivery mechanisms of chemicals as aid; these should be developed as part of a national policy in Afghanistan and as part of the project's procurement. Safety equipment is ordered separately, which results in the necessary gear arriving at a different time to the pesticides. In order to overcome this problem, it is concluded that orders of safety equipment should be included with every pesticide order and that this be made the responsibility of the supplier of the pesticide or sprayer. As a guide: one pair of gloves should be supplied for every 5 litres of chemical and one pair of protective overalls for every 40 litres of chemical; one pair of gloves and one pair of overalls should be supplied with every sprayer ordered.

WFP has developed special shipping instructions to be followed for consignments ordered for northern Afghanistan and they should be referred to when ordering chemicals. Note that for shipping containers it is a one-way trip to Afghanistan (see Appendix 10).

ii) Suitability of pesticide containers: There have been numerous incidents over the past four years of pesticides being received in inappropriate containers. The project, for example, received a consignment which was damaged during transportation to Afghanistan. The containers were clearly unsuitable. Since the project's programme is farmer based, containers must be small and durable. Containers designed for the bulk transportation of chemicals are not suitable. Ideally, chemical containers should be between 1 and 5 litres in size. PET containers are promising as far as durability and impact resistance are concerned. Metal containers of 10 litres and more often suffer damage during transportation on poor roads, and losses of up to 30 percent have been incurred during transportation to and within Afghanistan. Each consignment should also be ordered with sufficient extra empty containers to allow for chemical in damaged containers to be decanted. As a guide, it is recommended that sufficient extra containers be provided, with warning labels attached, to allow for 5 percent of the consignment to be decanted if necessary. See Appendix 10 for recommended specifications of chemical containers for use in farmer-training programmes in Afghanistan. 
iii) Warehousing: Since many of the public buildings in rural Afghanistan are in disrepair, the absence of proper warehouses restricted the area that could be reached by the project, as the number of secure distribution points is limited. Two high priority areas were identified by the project: Sarepul and Herat. Land was allocated by the local government authorities. In Sarepul, a new warehouse was built. In Herat, a building that had fallen into disrepair was allocated for renovation by the Government. The Herat warehouse repair is still continuing and should be finished by the end of the project.

iv) Labelling of pesticide containers: Containers sent from overseas arrived with English labels. Relabelling in Afghanistan is a time-consuming and laborious business and every effort should be made to have all pesticide labels in Dari or Farsi prior to shipment. The project should, in future, supply translations with Purchase Orders, which can then be transmitted to the supplier.

\subsection{SUB-PROJECTS CARRIED OUT UNDER AFG/92/009}

The FCP coordinated several small plant protection projects in Afghanistan.

\subsubsection{Desert Locust Project UNO/AFG/021/UNA}

A small project was initiated utilizing UNOCHA and USAID funds (US\$54 000) to provide plant protection training, inputs and monitoring for Desert Locust in southern Afghanistan (Project UNO/AFG/021/UNA). Although no infestations were reported, the project successfully reached many remote areas in the south of Afghanistan that had previously been without access to any plant protection assistance, and it has opened up the way for further plant protection activities in the region. A separate consultancy report has been issued. The work conducted by this project on Desert Locusts should be continued by the ICP project.

\subsubsection{UNO/AFG/022/UNA and UNO/AFG/024/UNA}

These two UNOCHA-funded projects provided bridging funds to procure inputs, ensuring continuity in supply between the 1994 and 1995 cropping seasons. The FCP coordinated the procurement with FAO Headquarters (AGO and AGP).

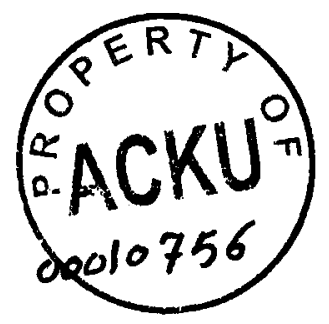




\section{RECOMMENDATIONS}

\subsection{INTRODUCTION}

In the evaluation of the following recommendations it must be kept clearly in mind that the project has primarily attempted to address the pest management needs of farmers growing one crop - wheat - in one part of Afghanistan, and has focused almost entirely on two pests, namely sunnpest and locusts. These species are not typical of the general insect pests which damage crops in Afghanistan, in that they are migratory, outbreak pests rather than chronic pests; what is more, because of this migratory habit and their otherwise complex biology, they are relatively difficult pests to manage. The fact that the project has been able to develop a management system for these pests, and deliver it to farmers, is - it is believed a worthwhile achievement, and would suggest that the general outline of the system should be applicable to other pest problems in Afghanistan.

\subsection{THE CROP EXTENSION NETWORK AND THE FARMER CERTIFICATION SCHEME}

While the training of the crop extensionists and the associated farmer certification scheme provided a means to link inputs to technical know-how, the system has tended to emphasize chemical control. To overcome this problem, it is essential that training aimed only at certifying farmers in the use of pesticides be avoided. Certification that allows farmers to purchase chemicals should be only one part of the farmer-training process. In the certification/training, an explanation of the economics of spraying must be made. As subsidies for chemicals are removed, farmers need to be encouraged to work out the cost of chemicals in terms of real production costs. The environmental costs of spraying also need to be explained in the same context. While the use of community-based extensionists is not a sustainable activity at present, they do provide a cost-effective means of delivering training to farmers.

Based on the experience gained by the project, the following specific recommendations are made in regard to the crop extension network:

i) While it is not at present self-sustaining, it is a cost-effective way of delivering training to farmers and should be continued in the forthcoming ICP project.

ii) The certification scheme should only be conducted as part of an overall training programme, so as not to encourage the unnecessary use of chemicals.

iii) Farmer training should be emphasized through the use of farmer field schools organized on a regular and continuing basis throughout the growing season. Preseason and post-season training is insufficient to instill IPM principles to be adopted by farmers.

iv) Possible means of developing increased sustainability of the network through community and private sector participation should be pursued.

\subsection{THE SALE OF INPUTS}

The input sale scheme seems to work and it offers many advantages; however, the process needs further development. An advantage of making farmers pay for inputs is that some of 
the basic economic and environmental realities of using chemicals can be introduced as part of the training. This provides an avenue for demonstrating to farmers non-chemical control techniques. Emphasis can also be placed on developing the farmers' understanding of pest ecology. This should enable farmers to recognize such things as beneficial insects (predators and parasites) and the stages of the insect growth cycle in relation to the stage of the crop. The potential insect damage to the crop depends on such a relationship. In general, farmers need to understand that, in many cases, spraying will not necessarily be beneficial and may even encourage pests. The certification scheme is relatively simple to manage and introduces some control over the use of chemicals. It is recommended that the certification scheme be continued in the follow-up project, and that the administration of the scheme be taken over by the PPQD; while the private sector participation be developed to incorporate the scheme.

It is further recommended that a gradual phasing out of the subsidies for chemicals takes place over the next five years, in conjunction with the continuation of the chemical certification scheme.

\subsection{SOCIO-ECONOMIC IMPACT STUDIES OF PROJECT ACTIVTTIES}

Further studies similar to the one carried out in Faryab need to be undertaken throughout the project area.

To improve feedback, FAO monitors and PPQD staff require training in Participatory Rural Appraisal (PRA) techniques. This will complement the "community-train-the-trainer" programme.

\subsection{Crop Protection INFORMATION SyStem}

i) The CPIS is still undergoing development and will need to be continued and extended by the follow-up project if its use is to be maintained. One of the objectives stated in the project document is the development of a "GIS" for plant protection. The CPIS should form the basis of this objective.

ii) The Management Information System used by the IPM project in the Philippines should be added to the CPIS.

iii) Given the work loads involved, it would not be possible for staff to properly coordinate the CPIS on a part-time basis and two full-time information officers need to be appointed in the follow-up project.

\subsection{CONTROL METHODS}

An integrated approach is needed as far as possible, as it is unlikely that one method will offer all the solutions. It is recommended that, because of the success of the previous work and its requirement for only a minimal operational infrastructure in the PPQD, the primary control strategy be one of crop protection by farmers themselves. This will, however, require much greater emphasis on the eventual development of village-level extension services. Refer to Appendixes 7 and 8 for details on the types of control methods that are recommended. 


\subsubsection{Locust control}

Overall, it is recommended that the control of $\mathrm{ML}$ and $\mathrm{IL}$ be restricted to the control of hoppers in band densities only, in both cropping and non-cropping areas. A better understanding of the natural factors influencing $\mathrm{ML}$ and $\mathrm{IL}$ outbreaks is needed. It seems probable that the periodic outbreaks of ML and IL in northern Afghanistan are associated with the regional populations itinerantly resident in some parts of central Asia every year. More contact is required with the plant protection authorities in the CIS countries bordering Afghanistan. Assistance and cooperation is particularly required in the area of monitoring annual breeding that could affect Afghanistan; the systematic exchange of information could be facilitated by FAO/ECLO. For specific technical recommendations, refer to Appendix 7 .

\subsubsection{Sunnpest control}

As far as possible, a range of control techniques involving cultural practices, improved wheat varieties and farmers protecting their own crops with the ULV chemicals in cases of acute outbreaks, should be tested and introduced for the control of sunnpest. Cultural practices, such as early planting and improved wheat varieties, offer the most hope. Monitoring has also to be continued, even when populations are in low numbers.

To instil a better understanding of the dynamics of sunnpest ecology, farmers need to be trained in how to monitor their own crop. Farmers can be taught what to look for, what the stage of the pest is in relation to the crop and whether it would be beneficial or not to spray.

To achieve the above, the following two requirements must be fulfilled:

i) Individual crop extensionists require more intensive training and this training should be carried out throughout the cropping season, rather than the current pre-season/postseason briefing and training sessions.

ii) Extensionists from the PPQD need to work more closely with groups of farmers throughout the season. The training principles and farmer field schools developed by the FAO Inter-Country Programme for Integrated Pest Control in Rice in South and Southeast Asia offer a good example of how to go about setting up such a training programme. Afghan trainers also need training in PRA techniques (see para. 3.3).

For specific technical recommendations refer to Appendix 8.

\subsection{THE FUTURE ROLE OF THE PPQD}

To a large extent the sustainability of all activities really depends on whether the PPQD will adopt and develop the farmer-based practices initiated by the project, or revert to the pesticide-based, subsidized, "top down" system that prevailed up to the war.

The training and advisory role of the provincial plant protection services needs to be supported. At present, the provincial authorities commit few resources to farmer training. Without some commitment on the part of the provincial governments to assist with these activities, a farmer-based training scheme will not succeed. Resources, such as offices, warehouses and vehicles, as well as manpower, have to be provided by the provincial authorities. 


\subsubsection{Sub-contracting the PPQD}

In many ways, the situation in which individual PPQD offices find themselves is similar to that of a poorly-resourced Afghan NGO, dependent almost entirely on outside assistance. There is scope to sub-contract the regional PPQD in much the same way as sub-contracts have been made with NGOs. This approach may offer several advantages: it provides the PPQD with resources, such as staff salaries, travel and operational and overhead costs; it provides a professional mandate and workplan that has to be completed. It should thus be possible to construct a system to train farmers with some autonomy. The use of the CSA with a provincial PPQD office also overcomes, to a certain extent, the problem of dual standards, which arises when contracts and resources are given to NGOs but not to local government authorities. Regional authorities would be able to assume greater responsibility in this area, while removing some of the administrative burden from FAO in the payment of individual staff salaries and DSA to PPQD officers. This is being tried in the spring of 1995 and the results shall be forthcoming in the new project. The use of funds generated from the sale of inputs in regional areas can also provide operational funds for the PPQD officers to carry out activities, such as monitoring, training of farmers and supervision of control operations.

\subsubsection{Privatization of the input delivery}

There is scope for cooperation between the PPQD and private traders. The importation of plant protection inputs, such as sprayers and chemicals, could be encouraged by developing the commercial aspects of providing inputs, in conjunction with the PPQD's training and advisory role. Initially, part of the proceeds from the sale of the inputs could be directed towards meeting the running costs of the PPQD. It is recommended that private traders be involved in the procurement of plant protection inputs as far, and as soon, as possible. The procurement of inputs through private enterprise will have to be undertaken in conjunction with the training and certification scheme. Some form of legislative control would eventually be required to regulate pesticide importation, formulation, distribution and use, probably through a revision of the existing legislation. In the short term, it is important that pesticides are not diverted past the farmer training programme of the new project if private traders are to be used.

\subsubsection{Visits and staff exchange within Afghanistan}

Staff from the Kabul office of the PPQD are generally unable to visit provincial offices on a regular basis, due to poor transportation and communications and political differences. In 1994, the project facilitated inter-regional links between central and provincial PPQD staff, by sponsoring the travel of Kabul PPQD officers to the field. This approach should be continued, especially during the cropping season.

\subsubsection{Facilitation of bilateral and multilateral links within south and central Asia}

At present, Afghanistan is generally unable to participate in multilateral and bilateral plant protection programmes. The project should be in a position to act as a focal point for contacting the PPQD and involving the officers in such things as regional conferences, seminars and workshops. It is recommended that the forthcoming project take the lead in 
providing PPQD staff with access to multilateral and bilateral programmes, especially in the field of IPM extension.

A contingency which could be covered by bilateral agreement is the possible need for aerial spraying of locust swarms and bands. Uzbekistan, Iran and Pakistan have fleets of spray aircraft which could be used to spray locusts from the air and are therefore a potential source of assistance. It should be emphasized that such an agreement should only cover emergencies - Desert Locust swarm invasion or widespread hopper band formation - and such events are exceptional and rare. For further details, refer to control options in Appendix 7.

\subsection{IDENTIFICATION OF NEEDS AND SUPPLY OF PLANT PROTECTION RESOURCES}

The initial emergency projects and the response developed by the FCP was, in part, a reaction to the lack of farmer access to plant protection options, and, fundamentally, to the lack of inputs. Some mechanism is required within the forthcoming project to provide a source of inputs. The ICP should be in a position to monitor specific plant protection needs in the provinces and assist in identifying individual projects, as well as funding sources for those high-priority inputs that cannot be readily obtained in Afghanistan. These inputs could be channelled through the ICP plant protection component, thereby ensuring that they are linked to the training of farmers. It is therefore recommended that ICP take a lead role in plant protection project identification and seek funding for the provision of inputs as specific problems arise.

\subsection{STUDY TOURS}

The years of war have isolated many professionals in Afghanistan. Study tours offer a good chance for PPQD, NGO and FAO national project staff to broaden their perspectives and update their skills, as well as allowing the transference of new skills.

It is recommended that the tours be based in the region, especially Pakistan, Iran, India and the CIS.countries to the north of Afghanistan, given the common culture and language. They should be of short duration and allow for follow-up visits to be made. They should also aim to re-establish regional inter-governmental links between technical agencies. This should encourage a more regional approach to plant protection problems.

Because of the regional approach of the project with the emphasis on farmer training, study tours should be preferentially offered to younger professionals working in the provinces.

\subsubsection{Secondment of PPQD officer(s) to Iran}

As a follow-up to the project study tour to Iran in October 1994, a further study tour should be conducted to allow regional PPQD officers to obtain practical experience with the Iranian plant protection service during the pest season (March-May). 


\subsubsection{Entomology/IIBC tour to Pakistan}

A study tour to the International Institute for Biological Control in Rawalpindi, Pakistan, is currently being planned. This will allow regional-based PPQD officers to gain experience in how to develop and maintain an insect collection; it will also improve insect identification skills.

A further aim of the tour is to establish relations between the IIBC in Pakistan and the PPQD in Afghanistan. As the PPQD is virtually without resources, they will have to rely largely on assistance from their neighbours to help re-establish their agricultural services. Links with international institutes are an important part of this process.

\subsubsection{Farmer Field School study tours}

To improve face-to-face training techniques and to increase the frequency of training, trainers need exposure to more up-to-date methods of farmer training. A good example of the type of process that would be transferable to the Afghanistan situation is the Farmer Field School concept developed by the FAO IPM project based in the Philippines. These schools are conducted with farmers on a regular basis throughout the growing season; lessons include the use of farmers' fields as demonstration plots. Farmers are encouraged to become involved in learning more about the ecology of the crop they are growing in an interactive and practical way. Afghan trainers would benefit from exposure to the methods and concepts used in this regional project. Since the schools are run at a local level by the plant protection services of the participating countries, they are a good model for the development of such an approach in Afghanistan. It is therefore recommended that study tours be conducted to one of the countries participating in the IPM programme (India, Sri Lanka, Indonesia, Malaysia). In addition, since the approach adopted by the project relies on the training of extensionists, new training techniques need to be introduced. Training in PRA for Afghan trainers is recommended. These techniques can be transmitted through training in Pakistan, where several organizations specialize in PRA.

\subsection{Pesticides}

Afghan farmers and PPQD officers are generally of the belief that a pesticide solution is the best and only method of pest management. There is relatively little use of agricultural insecticides, but this would appear to be largely due to lack of availability rather than intent. The use of pesticides may also be put down to the way in which the pests manifest themselves, particularly in the north: as acute localized outbreaks, rather than chronic problems. The longer-term programme should tackle this situation, to prevent dependency on pesticides from becoming the basis for pest management in the future.

A countrywide plant protection programme should be in a position to advise on the use of agricultural chemicals and quarantine requirements. This will assist in forming the basis for the rehabilitation of the PPQD as a regulatory body. Such a programme should also discourage the unwarranted use of chemicals and create a closer link between distribution and training, by applying standard conditions for the release of plant protection inputs. At present, this will most feasibly be achieved through the ICP project already underway. 


\subsubsection{BHC strategies}

A practical solution to the $\mathrm{BHC}$ problem is required. After making the not unreasonable assumption that nobody will be willing to pay for the high-temperature incineration of the BHC in Europe (approximately US $\$ 4000 / t$, plus transportation and handling costs), there are several options:

i) Whatever action is taken to dispose of the BHC stocks, urgent action is required to prevent the existing stockpiles from deteriorating and contaminating the surrounding areas. It is already too late for two large dumps: $1967 \mathrm{t}$ are held in open piles in Baghlan and $2913 \mathrm{t}$ are held in Kunduz under similar conditions. These stockpiles require rebagging and moving to covered warehouses. The environmental effects of BHC stockpiles in proximity to towns and water supplies could be dramatically reduced simply by moving them to safer areas for proper storage. The carrying out of this task in conjunction with WFP should be seen as a high priority for $\mathrm{AFG} / 94 / 002$. The area in Baghlan has been subject to periodic insecurity and it was hence not possible to carry out this work during 1994. The BHC project proposal for Baghlan relies on available local resources as much as possible, and the WFP Food for Work programme. It should be possible to carry out the work under the current circumstances.

ii) Once the BHC stockpiles are consolidated and those that are exposed stabilized and centralized in covered warehouses, there are several options:

a) Adoption locally for locust control or in termite-proofing of house foundations. Such options probably present only a limited environmental or public health risk; however, given the size of the stockpiles, it will take years to be disposed of; there is also the continuing risk that the $\mathrm{BHC}$ will be misdirected for use as a household insecticide, as it is commonly used to control fleas in houses.

b) Realistically the project will be unable to prevent $\mathrm{BHC}$ from being used for the control of locusts. If this is accepted, spray-operator training has to be improved and protective clothing must be provided. Truck-duster operators should work on a rotation basis, rather than one person carrying out all the loading or driving, to reduce exposure to individuals. A register of all $\mathrm{BHC}$ truck drivers and loader operators should be kept; they should be given special training and access to safety equipment; the FAO ICP project could assist in these areas.

c) Trading with Uzbekistan or Pakistan, where it is still used and where the means exist to apply large quantities of BHC over extensive areas at a low doses. Uzbekistan has a recurrent ML problem linked to the problems in northern Afghanistan. They also have no more stocks of BHC and are willing to trade Sulphur, Dimethoate or safety equipment for 200-300 $\mathrm{t}$ of BHC in 1995. The Uzbek Agrichemical Company has been contacted and the MAI in northern Afghanistan is pursuing this recommendation. 
d) Local incineration in the Pul-i-kumri concrete factory. It has been demonstrated that, under the right conditions, organochlorine compounds can be injected into a suitably-modified cement kiln, where temperatures are high enough to break it down. The problem is that, if temperatures fall below the required temperature, then highly toxic dioxins may be released. It is thought that this option is not appropriate for the disposal of stocks, because the cement factory in Pul-i-kumri lacks the quality control necessary to maintain the critical temperatures in the kiln. The factory is also located in the middle of the town.

Refer to Appendix 11 for more technical details on BHC in Afghanistan. 
Appendix 1

\section{PROJECT STAFF}

\section{Name}

Robert Nugent

Sher Hassan Hussaini

Zahir Habibi

Haji Ahmad Shar

Consultants

Michael Watt

Hans Dobson

Visits from FAO HQ

Mr Konuma, AGO (1)

Mr G. Schulten, AGP

Mr M. Scaillett, AGO

\section{Function}

Chief Technical Adviser

NPPP ${ }^{\mathrm{a}}$ - Operations

Manager

NPPP - Entomologist

NPPP - Field Officer

Plant Protection

Programme

(for total of 3 months)

Sunnpest monitoring/

training

Sunnpest monitoring/

training

Information system $\left(\mathrm{NRI}^{\mathrm{b}}\right)$

\section{Dates of Service}

Starting Concluding

$1.01 .94 \quad 31.03 .95$

$1.01 .94 \quad 31.03 .95$

$1.01 .94 \quad 31.03 .95$

$1.01 .94 \quad 31.03 .95$

$17.02 .94 \quad 10.07 .94$

$16.10 .94 \quad 13.12 .94$

$27.02 .95 \quad 31.03 .95$

$7.11 .94 \quad 16.12 .94$
Country Programme

Officer

Technical backstopping

AFG/92/009

FAO Divisional Chief field visit
March 1994

October 1994

October 1994 


\section{STUDY TOURS AND TRAINING CONDUCTED UNDER THE PROJECT}

\section{Study tours:}

1) Study tour to Iran.

Participants: 4 PPQD officers.

Dates: 26.10.94 - 12.11.94.

The objective of the tour was to allow Afghan PPQD staff to meet with their colleagues in Iran to compare control strategies for sunnpest. The tour allowed Afghan PPQD staff to observe monitoring programmes for overwintering adults and to obtain information on the organization and technical requirements for establishing a forecasting or early-warning capacity in Afghanistan.

A further output of the tour was the establishment of a link between PPQD staff and their Iranian counterparts; this may facilitate inter-country cooperation in the future. Such cooperation could take the form of the secondment of Afghan PPQD staff to participate in sunnpest control during the next season in Iran. In this respect, the proposed tour should be viewed as an initial contact for national technical staff with a view to furthering technical cooperation.

2) Insect growth regulator trials in Madagascar.

Dates: 27.04.95 - 18.05.95.

One FAO Afghan entomologist travelled to Madagascar to participate in Insect Growth Regulator trials for two weeks in April 1994. The experience gained allows Afghan staff to use IGRs once they become available in Afghanistan. The project intends to use these chemicals as an alternative to the currently-available ULV organophosphate chemicals.

\section{In-service training:}

1) The National Operations Manager for the project was sent to obtain training in Project Implementation and Financial Management at an FAO training course in Zimbabwe. October 1994, two weeks.

2) Training of two FAO Afghan staff members in the use of the CMIS, developed for the plant protection component of the Integrated Crop Production Project, which will commence in 1995. November 1994. 
Appendix 3

\section{INVENTORY OF PROJECT EQUIPMENT}

1 Vehicle "Toyota" Land Cruiser Mod. HJ80

Laser Printer "HP" Laserjet-4

2116.00

GPS Receiver "Magellan" 5000DX, complete

1596.00

Radio Communication "Codan" Mod. 8528 SSB

9529.69

Computer "Toshiba" Mod. 1960CS, 4MB

3200.00

Slide Projector "Kodak" Ektrapro-3000

1216.19

Generator "Honda" Mod. EM-2200XK1E

1468.28

Generator "Honda" Mod. EM-3000XK1E

2059.43

Scanner "HP" Scanjet IIIP

579.37

Printer "HP" Deskjet 560C

568.25 
Appendix 4

\section{TABLE OF ACTIVITIES FUNDED BY THE PROCEEDS FROM THE SALE OF INPUTS}

\begin{tabular}{|c|c|c|c|}
\hline Province (Centre) & Afs raised ${ }^{a}$ & Expenditure & Details of expenditure \\
\hline Balkh (Mazar) & 1215500 & - & - \\
\hline Faryab (Miamana) & 863750 & 800000 & $\begin{array}{l}\text { - warehouse } \\
\text { - PPQD office } \\
\text { - fuel }\end{array}$ \\
\hline Jozjan (Shiberghan) & 4165000 & 3335400 & $\begin{array}{l}\text { - two motorbikes } \\
\text { - office furniture } \\
\text { - two bicycles } \\
\text { - fuel }\end{array}$ \\
\hline Sarepul (Sarepul) & 2331600 & 1200000 & - warehouse \\
\hline Herat (Herat) & 48450300 & 39845000 & $\begin{array}{l}\text { - } 50 \mathrm{MT} \text { sulphur } \\
\text { - two motorbikes } \\
\text { - office repairs } \\
\text { - PPQD operational costs }\end{array}$ \\
\hline Samangan (Aybak) & 111229 & - & - \\
\hline
\end{tabular}

$$
\text { US\$1 }=\text { Af1 } 360 \text {. }
$$

Details of expenditure and balances left in regional accounts are held with the project. 


\section{Appendix 5}

AN EXAMPLE OF THE CERTIFICATE USED TO CERTIFY FARMERS 


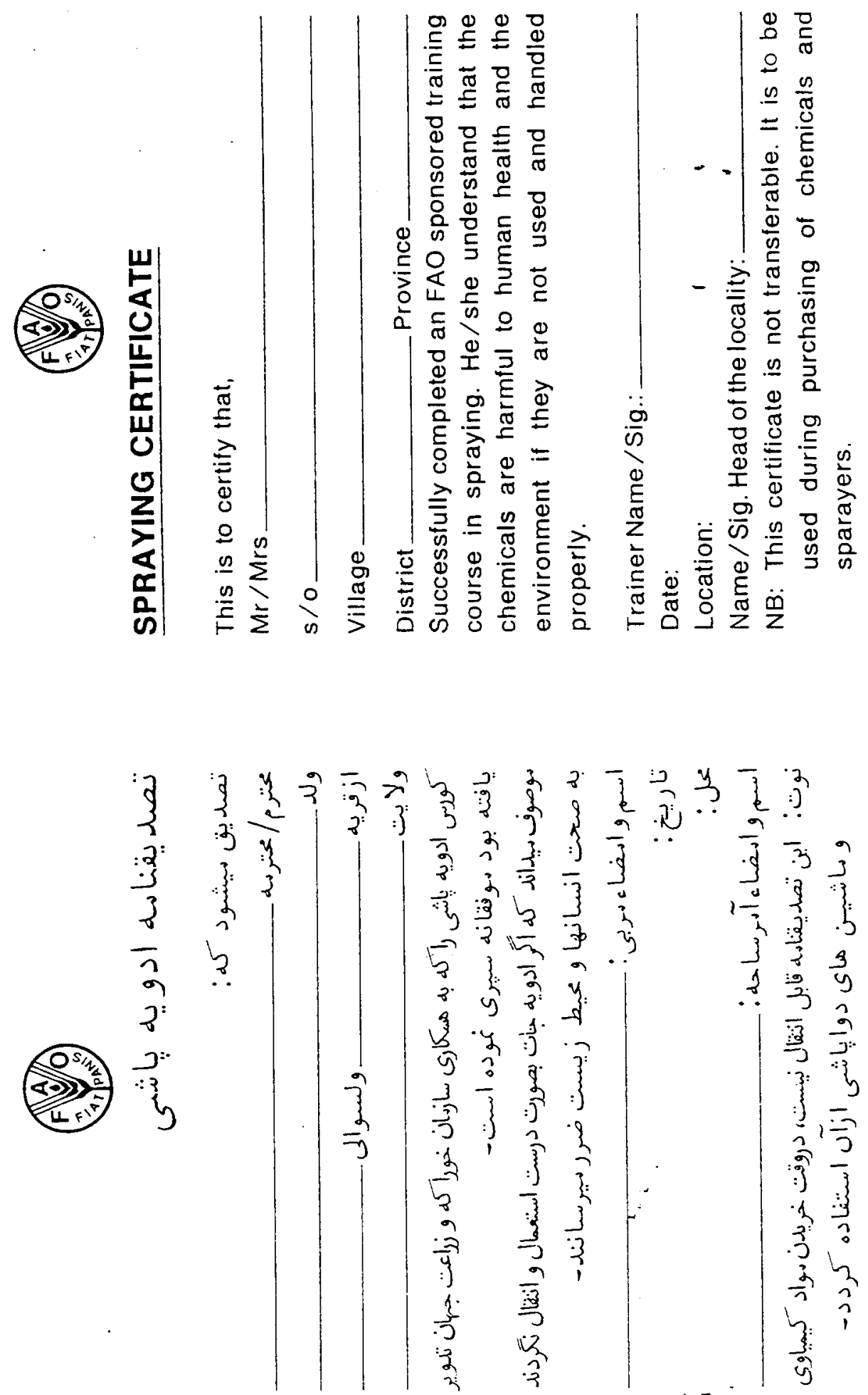

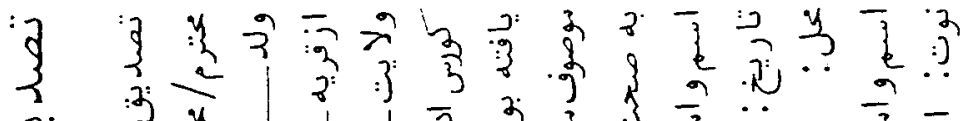

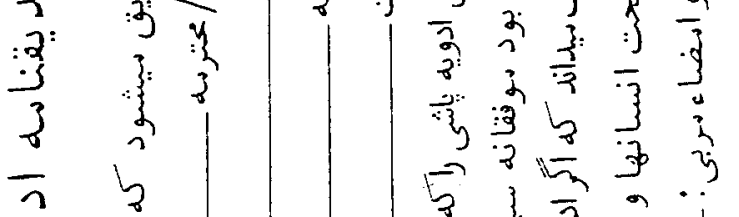

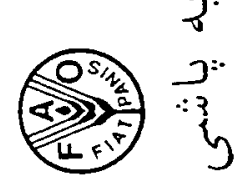



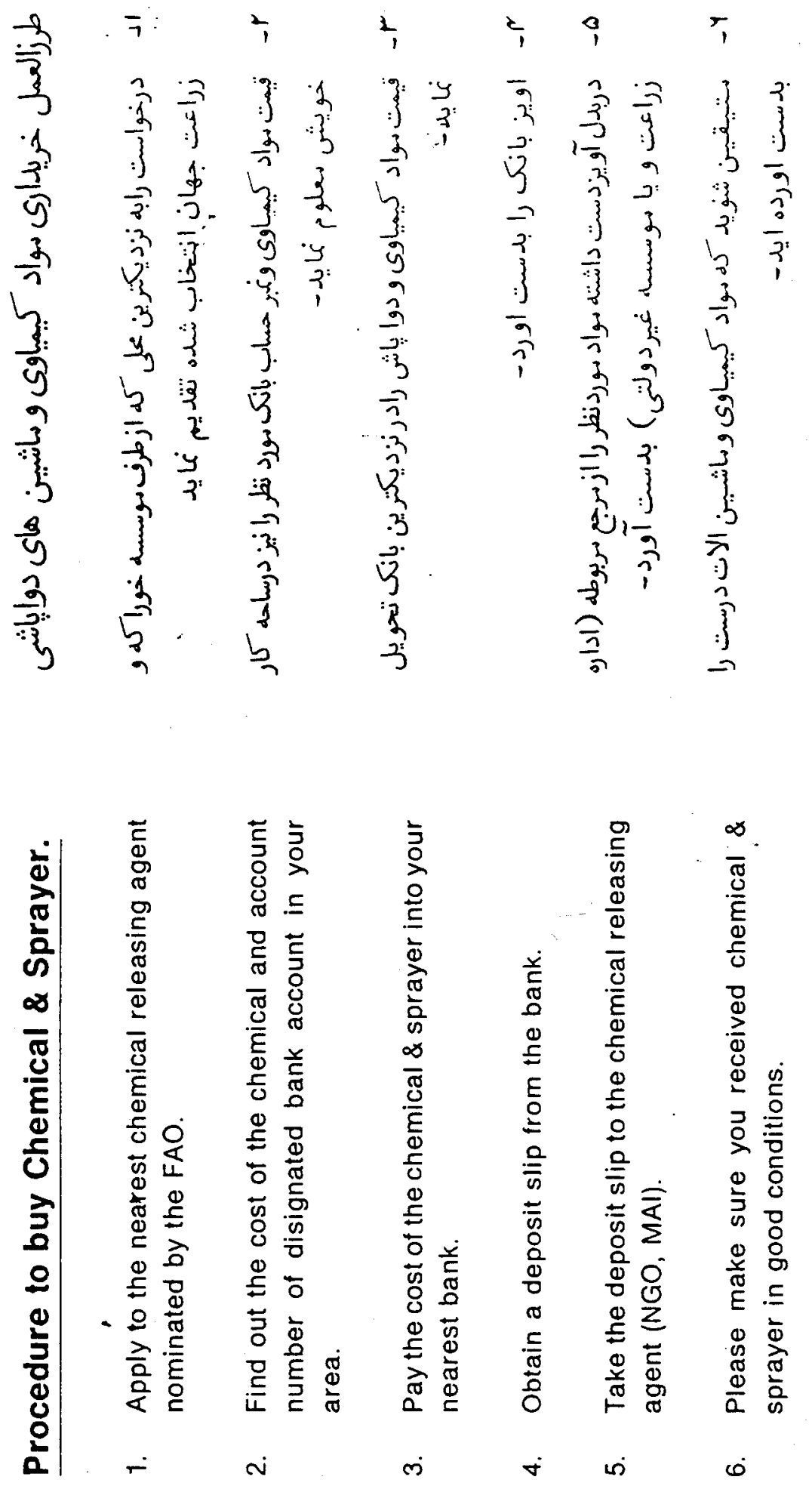


\section{TRAINING ACTIVITIES}

Training of various categories of trainees was carried out in the period March 1994 March 1995, in all the northern provinces, except Kunduz, Talaqan and Baghlan (due to insecurity in these two provinces).

Summary of training carried out between 1991 and spring 1995.

\begin{tabular}{lcrcccc}
\hline \multicolumn{1}{c}{ Year } & CE $^{\mathbf{a}}$ & ST $^{\mathbf{b}}$ & PPQD $^{\mathbf{c}}$ & Farmer & NGO & Monitor \\
\hline 1991 & 90 & 23 & 10 & N.A. & - & - \\
1992 & 77 & 8 & 0 & N.A. & - & - \\
1993 & 63 & 8 & 124 & N.A. & 46 & - \\
$1994 / 95$ & 142 & 15 & 212 & 24000 & 12 & 9 \\
\hline
\end{tabular}

Crop Extensionist.

Supervisor Trainer.

Plant Protection and Quarantine Department Officers.

\section{A6.1 COMMUNITY CROP EXTENSIONISTS AND SUPERVISORS (CE/ST)}

Communities were invited to nominate a representative to be trained as a "Community Crop Extensionist". These individuals were trained to train farmers in the fundamentals of locust and sunnpest control and the use of the ULV sprayers and chemicals. They were also briefed on how the communities could obtain inputs through the sale scheme. The "Community Crop Extension" network covered all the key wheat-growing districts in the north and the west of Afghanistan.

\section{A6.2 Provincial Plant Protection and Quarantine Officers (PPQD)}

PPQD officers were trained to train Community Crop Extensionists and were provided with the necessary training and extension material. They also undertook direct farmer training in the provinces.

\section{A6.3 NGO TRAINING}

NGO staff were trained and briefed on the programme, set out in the CSA agreement. A copy of the CSA is with AGO (FAO). Training of NGO staff from Faizabad (Norwegian 
Afghanistan Committee) and Bamyan (Oxfam) was undertaken. This training was part of two contractual service agreements signed with these NGOs and covered crop monitoring and training in Badakshan and Bamyan provinces.

\section{A6.4 CROP MONITORS}

Specialized training was given to selected crop monitors to carry out specific monitoring of pest infestations in key areas. The monitoring training initiated the sunnpest and locust monitoring system.

\section{A6.5 Farmier TRAINING}

The direct training of farmers was the responsibility of all trained extensionists. Community Crop Extensionists and PPQD officers were supported to train at least 20 farmers throughout the pest season. Over 24000 farmers are registered with the project as having received training in the use of the ULV, plus basic pest management training and briefings on the delivery process, all delivered by extensionists. The figure in the summary table is an accumulated total (1991-95). Over 8000 farmers received training in the 1994/95 period. The socio-economic study carried out in Faryab verifies the high degree to which the training has penetrated to the level of farmers. 


\section{LOCUSTS IN NORTHERN AFGHANISTAN - CHARACTERISTICS AND CONTROL}

\section{A7a.1 CHARACTERISTICS OF THE LOCUST OUTBREAKS IN NORTHERN AFGHANISTAN} In the previous four seasons, ML and IL outbreaks have been observed to have generally the following characteristics:

i) They are acute rather than extensive in nature, i.e. some areas are severely affected; however they are localized and not widespread.

ii) $\quad \mathrm{ML}$ is the dominant species, however IL causes serious damage in some areas.

iii) In any one area, the outbreak has not persisted beyond one generation; i.e. the following year the same area is not affected by serious problems.

iv) Local species of grasshoppers often compound the problem, with various species being involved as well as ML and IL. Once again, outbreaks of any species of locust or grasshopper do not seem to persist beyond one generation in any one area.

v) ML and IL hoppers and young adults that have bred locally appear to cause the most damage.

vi) When ML form gregarious hopper bands, they are readily observed on the dasht from a helicopter or survey aircraft flying at around $300-400 \mathrm{~m}$ above the ground (see Photo 1).

vii) ML eggs can become heavily parasitized; species of parasite unknown.

These observations have several implications for the control of ML, IL and local grasshopper species:

i) Breeding in the vicinity of crops appears to be more of a threat than the invasion of adults in crops.

ii) Aerial surveys are a possible means of carrying out monitoring for ML during the early spring in the dasht steppe.

iii) Indiscriminate spraying of low-level (non-gregarious) populations of ML, IL and endemic grasshoppers in the dasht is of dubious benefit in the control of the overall population and probably damages parasite populations. This annual practice needs to be stopped.

iv) Monitoring of laying swarms is important for locating egg beds. This methodology should be adopted rather than the traditional egg bed surveys that are carried out later in the year.

\section{A7a.2 OPTIONS FOR CONTROL OF LOCUSTS IN AFGHANISTAN}

\section{A7a.2.1 Egg bed surveys/destruction}

Egg bed surveys and destruction are probably ineffective because it is not possible to locate all the possible sites of the egg beds. It is more effective to try and locate laying swarms in the late summer and autumn as they are more visible. The location of the laying swarms 
must be recorded by GPS if possible and locations mapped on the CMIS. Egg beds need to be monitored for levels of parasitism in the autumn (October) and in the spring (March).

\section{A7a.2.2 Insecticides}

The use of insecticides will almost certainly remain the basis of locust control in Afghanistan, and the methods used therefore warrant careful consideration. Based on the experience of the project, spraying should generally only be carried out in the dasht when band density hoppers are located. Otherwise, spraying should only be carried out within or near crops, particularly if adults or hoppers are causing damage to recently-tillered wheat plants (mature plants can tolerate a high degree of vegetative damage without effecting the yield of the crop). effective):

Spraying is not recommended under the following conditions (as it is unlikely to be

i) Laying swarms of ML and IL. If they are located while laying then it is highly likely that they will have already deposited most of their eggs in the ground. It is more efficient to locate the egg bed and spray the hoppers when they emerge the following spring.

ii) Densities of locusts or grasshoppers not behaving gregariously.

\section{A7a.2.2.1 $\quad B H C$}

A highly-effective chemical against locust hoppers, widely used in Afghanistan in the past. It has a long residual effect in the environment, it is cheap and can be easily applied by untrained people. Its major drawback is that its long residual effect makes it an environmental problem. It is also classed as a carcinogen by the WHO and its use is banned in most other countries in the world.

It probably should not be used in Afghanistan unless one-off use is accepted as a means of disposal of accumulated stocks. BHC should not be applied within crops.

\section{A7a.2.2.2 ULV}

The ultra-low volume hand-held sprayer applying ULV chemicals (organophosphates or synthetic pyrethroids) was the main component of the crop protection campaign. Before 1991, the technology had not been used in Afghanistan. ULV chemicals have the advantage of not requiring mixing with water and only small amounts need to be applied per given area. This makes it easy to use in the dry extensive farming areas. However, training is required in its application and handling. It requires specialized, though relatively simple equipment, and as it is quite concentrated, it needs special care during handling. It does not have a long residual effect in the environment. The ULV sprayer has been adopted by farmers, as evidenced by their willingness to buy their own sprayers.

\section{A7a.2.2.3 Insect Growth Regulators (IGR)}

The project purchased a consignment of insect growth regulator (diflubenzuron), however it was lost in transit through Uzbekistan and no material was available to carry out trials. IGRs are chemicals which inhibit the growth of insects. They are specifically targeted at insects that go through several distinct phases of growth, such as the locust. They are less harmful to other non-target insects. They are of very low toxicity to mammals, and are 
therefore much safer to handle than the organophosphate chemicals currently in use. They have a long residual effect and, when sprayed as a barrier, may be effective in preventing localized crop damage. Their major drawback is that they are expensive (approximately three times the unit cost of ULV chemicals) and this will limit their application in low-value crops, such as rainfed wheat. The project also proposes to test mycopesticides Metarhizium flovoviride as a further alternative to conventional pesticides.

\section{A7a.2.2.4 Baiting}

Baiting has long been recognized as a method for controlling hoppers attacking crops. BHC baits were extensively used in the past, and bendiocarb and proporur are currently recognized as substitute alternatives. Where ULV is available, baiting with these materials could be an alternative control strategy. and should be tested during the course of the ICP project.

\section{A7a.2.3 Trenching}

Locust hoppers can be driven into hand-dug trenches. This certainly kills those that end up in the trench and it may be effective as a crop protection measure, however is time consuming and difficult to cover sufficient areas if locusts are behaving gregariously.

\section{A7a.2.4 Bilateral assistance with aerial control}

Iran, Uzbekistan and Pakistan have aircraft equipped to spray locusts from the air. In the case of a Desert Locust invasion in the spring in southern Afghanistan or extensive formation of hopper bands in the dasht of northern Afghanistan, it may be effective to use aircraft provided by a neighbouring country. This would only be required in the exceptional circumstances of a major outbreak with widespread infestations. Consideration needs to be given to establishing bilateral links with the neighbouring countries in case the need to use aircraft arose. The use of aircraft is not recommended for sunnpest and would only be feasible where trained ground support is available. Aerial control is not generally recommended and Afghanistan does not have the need to maintain and operate its own fleet of spray aircraft. 


\section{REVIEW OF INFORMATION ON LOCUSTS AS WHEAT PESTS IN AFGHANISTAN}

Please refer to Appendix 13 for references given in this section.

\section{A7b.1 MorocCan LOCUST}

Dociostaurus maroccanus (Thunberg) is a multivorous species that is one of the most serious pests of a large number of cultivated plants - particularly grain crops - in much of its distribution, which extends from the Canary Islands in Africa up to central Asia. It is characteristically found on semi-arid slopes or in semi-desert areas with abundant spring ephemeral vegetation, as it is favoured by a spring rain fall of $100 \mathrm{~mm}$ or more. Highdensity populations may be found where there is a mosaic of bare ground and long and short vegetation. Compact virgin soil is necessary for its existence, though this may be derived secondarily by the activities of sheep and goats. Hoppers show gregarious behaviour, advancing in a long line, which - though only about $5 \mathrm{~m}$ deep - may extend for several miles. Adults show swarm activity and flights extend in length during the day as the temperature rises; but, although this may result in a gradual spread of the affected area, the general location does not change. Sometimes limited displacement may occur; however, although the insects are unquestionably gregarious, both morphologically and in terms of swarming behaviour, this behaviour has rarely been seen to result in migratory flight. Gregarious-phase locusts are considerably larger than solitarious ones, besides showing morphometric and chromatic differences. The species is univoltine. The bare patches of ground in the mosaic vegetation serve as oviposition sites. Group oviposition has been observed and as many as 148 eggs have been dug from $1 \mathrm{~m}^{2}$. The egg pods may be in small earth pockets in rocky ground, just below the surface, or they may be deeper $(4 \mathrm{~cm})$ in firm soil. Oviposition is also recorded in favourable loose soil, in lowland slopes and in clumps of Cynodon dactylon. Eggs are laid about one month after adults appear - from June onwards - and they overwinter, hatching in March or April. Hopper development takes 42 to 55 days, and there are between 5 and 6 hopper instars.

The above summary is taken from COPR (1982), which gives an extensive bibliography, and also records the related species D. plornikovi (Uvarov) and D. crassiusculus (Pantel) from northern Afghanistan. Other important references are: Merton (1961), which describes the Moroccan Locust in Iran and mentions swarms invading the Janatalabad area in northern Iran from Afghanistan; Uvarov (1977), which deals entirely with the population dynamics of Moroccan Locust, including the effect of climatic conditions; and Latchininsky and Launois-Luong (1992), which synthesizes work on this pest.

In Afghanistan, the ML is found only in the north of the country, on the northern slopes of the foothills of the Hindu-Kush. According to Shamonine (1964), the permanent distribution is between 400 and $1000 \mathrm{~m}$. The limit is between around 1200 and $1350 \mathrm{~m}$, and as high as $1800 \mathrm{~m}$ in dry years; they were observed by the project in lower numbers in Bamyan at over $2000 \mathrm{~m}$. The southern limit passes along the mountain chain of the Hindu-Kush, to the east of Koh-i-Baba and Siah-Koh. The latter author indicates four foci of gregarization, situated in the districts of Mazar-i-Sharif (Balkh), Kattagan, Maymana 
(Faryab) and Herat. This distribution covers 1500000 ha of uncultivated and virgin land used for grazing. The vegetation in this area is steppe-type dominated by Poa bulbosa, Carex pachystylis and other ephemerophytic species (Shamonine, 1964). This author also mentions Agropyron repens, A. cristatum, Aegilops sp. and Hordeum sp. Agropyron sp. is most important in the majority of vegetation types: this type of vegetation forms, on the northern slopes of the foothills or in the river valleys, a mosaic pattern with the more drought communities of Aremisia sp., Alhagi camelorum and Erianthus ravennae and with patches of bare soil. The populations of grasshoppers most often found with the Moroccan Locust are Dociostaurus tartarus, Oxya fuscovittata, Acrida oxycephala, Calliptamus turanicus and Miosciirtus wagneri.

According to Shamonine (1964), several invasions occurred in the following periods: 1928-1934 (with peaks in 1931 and 1932);

1948-1953 (with a peak in 1952);

1956-1960 (with a peak in 1958).

This author suggests that periods of invasion in Afghanistan generally coincide with those of invasion in the central Asian foci in Uzbekistan and southern Tajikistan. More recently, the foci in Afghanistan are considered as very important and regularly produce gregarious populations, contributing to the outbreaks of plagues in central Asia during the middle 1980s (Latchininsky and Launois-Luong, 1992). However, the project observed that little to no survey work was carried out during this period, and the contention that northern Afghanistan is a source of plagues in central Asia would be difficult to substantiate empirically.

Although a large number of natural enemies of Moroccan Locust have been recorded elsewhere, there is little information on their occurrence in Afghanistan. The rosy starling ("Saach" in Persian) (Sturnus roseus) is recognized by Afghans as a predator of swarms. The common myna, Acriodotheres tristis, is also a common bird in Afghanistan and a predator of locusts (Roberts, 1991). Chandra and Singh (1981) report that seven species of lizard prey on acridids, and were introduced into Sardinia for control of the Moroccan Locust. Greathead (1976) and Sondbo (1992) noted blister beetles in this Moroccan Locust study area.

Locust destruction to crops was first recorded in Afghanistan in 1935 (Edwards and Rann, 1991), although their presence - and farmers' efforts to control them - certainly date back to ancient times. It was not until the advent of synthetic insecticides after World War II that any large-scale attempt to control Moroccan Locust was made in Afghanistan; and from 1980, the Government of Afghanistan received large-scale assistance from the USSR, in the form of gamma BHC. As a result, considerable areas were treated, largely through the application of $12.5 \%$ dust at about $20 \mathrm{~kg} / \mathrm{ha}$, using motorized dusters mounted on Gaz trucks. Areas treated between 1950 and 1961 are given in Table 1. 
Table 1. Area treated with pesticides for control of Moroccan Locust in Afghanistan between 1950 and 1961.

\begin{tabular}{cc}
\hline Year & $\begin{array}{c}\text { Area treated } \\
\text { (ha) }\end{array}$ \\
\hline 1950 & 19921 \\
1951 & 45870 \\
1952 & 51509 \\
$1953-5$ & not available \\
1956 & 10281 \\
1957 & 16895 \\
1958 & 33546 \\
1959 & 46336 \\
1960 & 52456 \\
1961 & 1200 \\
\hline
\end{tabular}

Source: Shamonine, 1964.

These areas are certainly considerably less than the total area infested in years of peak infestation - a survey conducted in 1989 suggested that at least 500000 ha were infested with locust and/or sunnpest (SCA, 1990). This upsurge may have resulted, in part, from the USSR-supported control operations being terminated in 1984; this led to a number of bilateral, multilateral and NGO projects aimed at limiting its economic impact, including a USAID-sponsored project in Badghis Province (Edwards and Rann, 1990) which was of interest for the following reasons:

- It reports on the successful and safe use of Malathion ULVA sprayers, as an alternative to BHC dust application (Rann, 1991).

It included egg-pod destruction as a component of control operations, for which farmers were to receive payments in the form of wheat, cooking oil, batteries or cash. There is no evidence that this work was actually carried out, but it was reported that Moroccan Locust egg-laying sites were reasonably easy to find and identify. Local herdsman and farmers apparently often see them (Rann, 1991).

The control approaches used by AFG/92/009 and earlier UNOCHA-supported projects have been reviewed by Dobson (1991a, 1991b and 1993) and Gruys (1992). Sandbo (1992) reports on control trials with BHC and deltamethrin against Moroccan Locust in Badakshan Province, and showed that, while the recommended dosage of $2.4 \mathrm{~kg} / \mathrm{ha}$ a.i of gamma BHC dust should be maintained, rates of deltamethrin as low as $3 \mathrm{~g} / \mathrm{ha}$ a.i gave greater than 90 percent mortality when applied by Micro-ULVA.

\section{A7b.2 Italian Locust}

There appears to be general agreement that the Italian Locust (Callipramus italicus (L.)), while an important pest species, causes less damage than Moroccan Locust. There may, however, be some confusion about the species involved. Stolyarov (1971) records a number of Calliptamus species from Afghanistan. These include $C$. barbarus (Costa) and $C$. turanicus (Trb.), both recorded as damaging cereals in Afghanistan. The following 
information on Italian Locust is summarized from COPR (1982), -which also gives a comprehensive bibliography; references to the species in Afghanistan include Jago (1963), Cotterell (1953) and Mischenco (1952).

The species is widely distributed: from the northern Mediterranean basin to the east, up to the former USSR, across Switzerland, Germany and south to Pakistan. It can cause significant damage to a wide range of cróps, including cereals, oil crops, fodder plants, vegetables and fruit trees.

In Afghanistan, breeding grounds extend up the northern mountain valleys to an altitude of $1000 \mathrm{~m}$ and also in low-lying steppes to the frontier with CIS. In the central Asian oases, it lives in field borders, fallow, wastelands, neglected orchards and lucerne meadows, sometimes with saline soils with Cynodon dactylon, and is specially prevalent in dry steppe zones. It is particularly common in irrigated crops and is tolerant of a wide range of semi-arid soils and climate. Though generally considered a lowland species, it is found in Afghanistan at up to $2700 \mathrm{~m}$ above sea level.

It is generally herbicolous and usually herbivorous, but also eats cereal grasses, although it generally avoids wild ones. Adults are known to be subject to phase change in both morphometries and their behaviour ranges from complete solitariousness to occasional, or rather, incomplete gregariousness. The degree to which this occurs, and fluctuation in population, vary greatly according to whether or not the climatic conditions favour sustained flight. This usually occurs at around noon on very hot days, the swarm moving with the wind. Small swarms may travel 20 to $40 \mathrm{~km}$, but larger ones go further, up to $220 \mathrm{~km}$. Unlike less gregarious species of the genus, it does not seem to be attracted to light and is thus probably not night flying. In west Pakistan, it appears to form only loose swarms and flights extend over limited areas.

The species is univoltine, with egg diapause in autumn and winter. Eggs are laid in the dry soils of the sage-brush (Artemisia austriaca) steppes, and also in loose, dry soils. These conditions may result from fallow land ploughed two or three years previously being close to present crops, and can result in a serious threat to adjacent crops. There are five hopper instars in the male and six in the female. In the CIS, hatching occurs from late April to mid-June. Development of all instars is complete in 30 to 45 days and adults appear from the end of May to the end of June. Eggs are laid from June to July in Afghanistan and group laying has frequently been recorded. Adults die off at the end of summer.

Uvarov (1977) discusses the population dynamics of the species and indicates that populations are likely to increase following warm dry years, but suddenly collapse after cool, wet ones.

Little specific information on the control of Italian Locust appears to be available, and in Afghanistan it has been assumed that measures effective against Moroccan Locust can be effectively applied also to $C$. italicus. Pastre et al. (1989) report on the effectiveness of $10 \mathrm{~g}$ a.i./ha of deltamethrin in Tunisia against Calliptamus sp.

\section{A7b.3 DESERT LOCUST AND OTHER LOCUSTS/GRASSHOPPERS}

COPR (1982) reports that 50 locust or grasshopper species, that may have some significance as crop pests, have been recorded in Afghanistan. Apart from Moroccan and Italian Locust, the list includes a number of other potentially economically important species, including Desert Locust pest, but serious damage in Afghanistan is infrequent. As Desert Locust does not overwinter in Afghanistan, the key to the prevention of serious damage is activities aimed 
at the prompt detection and reporting of any swarm invasion from Pakistan or Iran in the spring. Other records from Afghanistan reveal the Sudan Plague Locust, Aielopus simulatrix, the Migratory Locust, Locusta migratoria, Oedalus senegalensis and the Egyptian Locust, Anacridium aegyptium. 


\section{SUNNPEST IN NORTHERN AFGHANISTAN}

\section{A8.1 BACKGROUND INFORMATION}

The pentatomid, Eurygaster integriceps put. (sunn, suni or sunnpest (English); kafshak, khasafak (Dari)), has long been recognized as a serious pest of wheat in Afghanistan (Siddiqi, 1973). Remaudiere (1959 and 1961) and Donskoff (1966) report on outbreaks in the late 1950 s and early 1960s. Siddiqi (1973) records a number of related pentatomids also affecting wheat, including E. testudinarius (Geoffr.), Aelia melonata Fab., A. rostrata Boh., Raphigaster nebulosa Poda., Carpocoris pudicus var. guscispinus Bch., C. purpureipennis DeG., Dolycoris baccarum L. and Eurydema pulchrum West. Brown (1962) records Eurygaster integriceps and Aelia melonata from Maimana, but found no other species of either genus from Afghanistan in the British Museum. Edwards and Rann (1990) indicate that both $E$. intergriceps and $A$. rostratra were involved in the serious pest upsurge during 1989-90 in northern Afghanistan, but $E$. integriceps was not found amongst material collected from Faryab and Takhar provinces during this outbreak (Harvey, 1992). The most common species collected was Dolycoris pencillatus Hovrath, but Carpocoris coreanus Distant, Eurydema sp. and Aelia melanota were also present. A similar complex of species occurs in Iran (Javahery, 1993), where Eurygaster integriceps is the most important species: Aelia spp. and Dolycoris spp. occur in rainfed wheat, and populations occasionally increase to high levels; Carpocoris spp. is a secondary pest of cereals in some regions and is "rarely" found on wheat plant with Eurygaster and Aelia spp. Javahery states that all four genera damage wheat and barley in a similar fashion: they attach to the stem of young plants, causing them to wither and die before the formation of heads; they also feed on the developing grains and secrete certain enzymes that affect the gluten quality of the grain; consequently, the resulting flour loses its baking quality after even only a small percentage of the grain is punctured. Bread made from flour milled from damaged wheat will not stick to the sides of ovens and is thus often lost during baking, according to farmers interviewed in Ghulran, Herat Province. Javahery (1993) also indicated that the life history of all genera is similar, in that they are univoltine, and diapause in the adult stage for four to six months starting in summer and ending in spring. Some differences in migratory behaviour are noted, particularly in the distance moved to aestivation sites in summer and to overwintering sites in autumn.

The literature on E. integriceps, and to a lesser extent Aelia spp., is extensive, and Talhouk (1969) gives useful reviews for both. Much of the work on E. integriceps is in Russian and a great deal of this has been summarized in four volumes edited by Fedotov (1947-1960). Khan (1964) gives a useful review in English of research and control of sunnpest in the USSR. Brown (1962) records detailed studies on the ecology and biology of $E$. integriceps. A series of country reports and invited papers (presented at the FAO/ICARDA Expert Consultation in 1993) provide a valuable update on the present status of sunnpest research and control activities in the Near East Region (FAO, 1993); these include a detailed report on the sunnpest problem in Afghanistan (Hussaini, 1993). It is clear from Russian literature and from papers presented at the above-mentioned Expert Consultation, that the potential for the development of an integrated approach to sunnpest 
exists, and it is therefore surprising that the consultation showed that control operations in the region are solely chemical based and the responsibility of governments.

\section{A8.2 Technical results of the aCtivities undertaken by the Field Crop Protection Project}

\section{A8.2.1 Species involved}

Field observation made during the 1994 cropping season confirms that Dolycoris is the most frequently observed species in wheat field in northern Afghanistan. The status of other species during 1994 can be summarized as follows:

- $\quad$ Aelia melonata essentially attacks crops late in the season; heavy infestations were noted, for instance, in mature crops in Ghulran in June 1994; this species is recognized by its Farsi name in the northwestern provinces, which translates as "dry feeder".

While generally recognized as the most conmon pest species elsewhere in its distribution, $\boldsymbol{E}$. integriceps appears to be relatively less important in northern Afghanistan, although a significant population was found during 1994 in the northern areas of Faryab and Jowzjan, infecting irrigated wheat in low rainfall areas.

- Carpocoris coreanus appears to be the least important of the four species, and its status is similar to that of Carpocoris spp. in Iran. Significant populations were nevertheless found relatively early during the 1994 cropping season in Ghulran and Khusk districts of Herat.

A better understanding of the relative importance of the four species will only be achieved through careful monitoring over a number of seasons.

\section{A8.2.2 Monitoring and trials}

The project has established monitoring sites in Herat and Faryab provinces. These will also be the sites of non-replicated variety trials of a selection of short-duration wheats from Pakistan, together with a few elite local varieties, designed to compare their performance under farmer conditions in dryland wheat areas, in terms of both yield and pest/disease incidence. A set of 13 varieties were planted in each site in winter and spring (1994/95), and will be monitored for pest (including sunnpest) populations during the 1995 crop season. Efforts will also be made to estimate and collect levels of egg parasites in sunnpest. The monitoring aspects of these trials should continue for as many cropping seasons as possible.

The most remarkable feature of sunnpest biology is their annual life cycle, which makes them suitable for the relatively extreme climate conditions in which they live. The insects live for one year, but only about three months is spent as an active insect feeding on graminaceous plants (including wheat) and some broadleafed cereal species. The rest of the year is spent in the adult stage in a state of almost complete inactivity, and for this resting period it migrates long distances - usually to high altitudes in mountain areas, where they shelter under plants. This resting period has at least two phases: aestivation during the hot dry summer months that follow the harvest of cereal crops, and hibernation during the cold, often severe winter months. In spring, the adults that survive migrate back down to the field and another feeding and reproductive cycle begins. It has been suggested by various authors 
(e.g. Brown, 1962) that monitoring of the overwintering population could be useful for forecasting future sunnpest population trends, although there appears to be little information on the relationship between the number of resting adults in aestivation/hibernation sites and the loss of crops in field later.

During 1994, the project developed a survey method for monitoring the overwintering population in Herat, Faryab and Jozjan provinces; this provides a series of interesting "snapshots" of the status of the overwintering population in a number of discrete and often notably inaccessible sites; but, in general, it leaves a large number of questions unanswered as to the aestivation/hibernation pattern of the four species in northern Afghanistan. Perhaps the most significant finding of these surveys was the identification during October and November of large populations of $D$. pencillarus under scrubby ground-clinging bushes, known as "ghosbeh" in Farsi (probably Arternesia and Astraglus spp.), at high altitudes in mountains areas which lie generally south of the rainfed wheat-growing areas in Herat, Badghis, Faryab and Jowzjan provinces, in which Dolycoris apparently is the dominant pest.

Details can be found in reports made by project staff, but very high populations (up to $15000 / \mathrm{m}^{2}$ ) were found in some locations. There is evidence of a second migratory movement in late autumn, although this appeared to be at a higher elevation, and perhaps from the northern to the southern slopes, rather than the downward migration reported by a number of authors for Eurygaster. For example, at two locations northeast of Herat, large, apparently migrating, populations were observed late in October, and in late November. A population of Dolycoris - apparently resting in trees, grass, etc., since late June, at approximately $1500 \mathrm{~m}$ south of Qaysar in Faryab Province - was reported to have moved away in a southerly direction, and at about $2000 \mathrm{~m}$, resting adults were found under ghosbeh and other bushes. Many authors report considerable mortality during the overwintering period, and in one area, south of Almar in Faryab, a large number of dead Dolycoris (mostly, it is believed, at least one year old) were found together with a few living adults, again under ghosbeh and other bushes. Among the dead insects were a significant number affected by a white fungus; this has been identified by NRI (UK) as Beaunvana bussiana.

With the exception of one location south of Khusk-i-Kuhna, where Aelia melinonata was the most numerous overwintering species, very few resting adults of any species other than $D$. pencillatus were found in the mountains in the northern areas; however, at an elevation of less than $500 \mathrm{~m}$ in both Faryab and Jowzjan, where significant infestations of Eurygaster occurred in mainly irrigated wheat in 1994, aestivating adult populations apparently remained near wheat fields, resting in grass clumps, under clods of soil etc. until mid-November, and a few adults were found in late November under soil clods in Qaramqul District, Faryab.

No evidence concerning migration to hibernation sites was obtained, although this presumably occurred.

Climatic condition is important, both in relation to the survival of overwintering populations and to feeding and reproduction in the wheat fields. There seems to be general agreement that usually warm and dry conditions in late summer and autumn, and warm conditions - or temperatures fluctuating between high and low - in winter, are unfavourable; and that warm weather and low rainfall in spring are most favourable to the insects. The project has begun with the establishment of rainfall gauges in a number of locations within the project area; it is essential that these are supplemented at least by temperature monitoring equipment. 
There are three occasions in the life cycle of sunnpest when numbers of insects have been assessed for purposes of survey, forecasting or loss estimation.

i) Counting of overwintering adults at resting sites: This work began at the 1994 programme meeting held 1-5 December, and the project has developed a standardized survey method for sunnpest from year to year, rather than obtaining any absolute estimate of the overwintering population.

For this reason it is desirable that:

- $\quad$ counts be made at the same site at the same date each year;

- $\quad$ counts be made in autumn and spring of each year so that winter mortality can be assessed;

- numbers of sunnpest be expressed in terms of number of each sex, living and dead, of each species.

Once these figures are available for two mountain sites in Herat, one site in Faryab and one in lowland irrigated wheat areas in Faryab (where aestivating populations of $E$. inegriceps have been located), attempts can be made to correlate the overwintering population with field populations in the following season; and, if a valid correlation can be established, it may then be possible to use overwintering survey data to predict the intensity of sumnest infestation in the following season.

ii) Counting of adults that have migrated from overwintering sites into wheat fields in spring: This can be done by counting insects in quadrat from several fields in the same area at different distances from overwintering sites. Sweep netting or counts per plant have been used in the past for estinating population, but quadrat counts are preferred. A standard survey method has been developed, based on methods described in Banks and Brown (1962). Data obtained from the locust surveys should give additional information on the level of sunnpest infestation to be anticipated later in the season, and contribute to the accumulation of sufficient data to allow the establishment of threshold levels above which control operation could be justified.

iii) Counting of nymphs and new generation adults on wheat, using the same fields and methods described above: The detection of nymphal stages is probably the key to successful control of these pests, and efforts should be made to develop a practical monitoring method that can be used by farmers; such a method should incorporate threshold levels that farmers can utilize as a guide to the use of control options.

\section{Some additional points:}

During the monitoring of fields as described above (ii and iii), collection should be made of sunnpest egg masses and estimates of egg parasitoid levels should be made. Parasitoids that emerge should be collected for identification.

Meteorological data (preferably rainfall, temperature and wind direction/intensity) should be made available for each monitoring site.

Much of the survey/monitoring activity will involve host plants other than wheat, and additional information on the identification of these hosts and their relationship to sunnpest ecology is needed; the recruitment of an A fghan Botanist is therefore recommended. As with 
the identification of botanical species, continuing development of the project's ability to accurately identify the pests involved is essential to survey/monitoring activities as well as to other project activities.

The implementation of this monitoring programme will:

assist in estimating sunnpest infestation levels in a time frame that allows for the more efficient implementation of control measures;

help to develop a monitoring system that can be used by farmers in making control decisions.

\section{A8.3 FaO on-farm wheat varietal trials in Herat Province}

i) Little or no work on varietal improvement has been carried out in the rainfed wheatgrowing areas of northern Afghanistan for the past 15-20 years, and observations by project staff over the past four years indicate that varieties have degraded, are mixed, yield poorly and have high susceptibility to pests and diseases, including sunnpest, locusts, smuts and rusts. Other reports indicate that there is a strong perception of the need for improved seed among farmers in the project area.

ii) In 1994 the project initiated a limited number of on-farm wheat varietal trials, aimed at comparing the performance of selected short-duration varieties from Pakistan with the best available local varieties, in terms of pest incidence, disease susceptibility and yield.

iii) The possibility of pest and/or disease tolerance is based on the hypothesis that:

- short-duration, rapid-maturing varieties and/or winter planting may avoid serious attack by sunnpest;

- $\quad$ some varieties may possess inherent resistance to sunnpest;

- $\quad$ varietal resistance is the key to limiting losses caused by rusts;

- $\quad$ varietal differences in susceptibility to smuts and bunts are known to occur in wheat;

high-yielding varieties may compensate for losses from pests or diseases.

iv) In November 1994, 13 varieties (9 improved and 4 local) were planted in nonreplicated randomized blocks on farmers' land in three locations in Ghulran and Khushk districts of Herat Province. These plantings will be repeated in March, so that the susceptibility and yield resulting from winter and spring planting can be observed. One additional short-duration variety from Pakistan will be included in the spring plantings, and an additional location in Khusk-i-Khona District will be included. Observations will be based on those used for the CIMMYT International Winter Wheat Screening Nursery, and additional sunnpest and locust monitoring will be carried out at weekly intervals following standard procedures developed by the project.

v) Depending on the results of these preliminary trials, consideration should be given to extending this work to other dryland areas in northern Afghanistan and to obtaining 
varietal material from other sources, including CIMMYT and FCARDA. All future work will be done in close coordination with the seed production component of the crop production project (AFG/94/002).

vi) The wheat trials will also be used as demonstration plots for training purposes and monitoring sites for the sunnpest monitoring scheme.

Types of wheat varieties used in trials

1. PS - 91

2. Rasoul Khani

3. Ciano

4. Pak -81

5. Zardina

6. $\quad \mathrm{KYB}-87$

7. Surkak

8. Alburz

9. Zarghorn -79

10. PS -85

11. Pashan -90

12. Inqihab -91

13. HD -2285

\section{Source}

AFG/92/008

Rabat Sangi (local)

Urdukhan farm (local)

AFG/92/008

Badghis (local)

AFG/92/008

Local variety from each trial location

AFG/92/008

AFG/92/008

AFG/92/008

AFG/92/008

AFG/92/008

AFG/92/008

\section{A8.4 OPTIONS FOR CONTROL OF SUNNPEST}

\section{A8.4.1 Farmer control and ULV}

Project activities to date have been based on the application of organophosphate insecticide (principally dimethoate, but also sumi-combi-alpha), using hand-held ULV applicators. The success of this technique is that it has allowed farmers to protect their own crops, and it does not appear to have been used elsewhere for sunnpest control. Future activities should be aimed at the farmer, as he is more aware of controlling new generation nymphs, rather than waiting until large populations of adults build up with concurrent heavy crop losses. 


\section{A8.4.2 Biological control}

The importance of egg parasites in regulating sunnpest populations is often mentioned in the literature. Their status in Afghanistan is largely unknown, and monitoring activities should aim to improve information in this regard. As far as possible, the selective use of insecticides should be minimized to conserve as many natural enemies as possible. Fungi may have potential for destroying overwintering adults if their application is feasible.

\section{A8.4.3 Destruction of overwintering adults}

The destruction of overwintering adults would be a very difficult control strategy, and the likelihood of its having any significant effect on pest status is doubtful. The suggestion of destruction - by burning or otherwise - of the bushes in which hibernation occurs should be resisted for both ecological and practical reasons.

\section{A8.4.4 Cultural practices}

Various cultural practices - mainly the use of resistant/tolerant varieties, crop substitution with barley, trap cropping, fall sowing, rapid harvesting, and two-step harvesting - have all been suggested as possible control strategies. Careful assessment of their practicality is required if there is to be a likelihood that farmers will adopt them. Of the above suggestions, the possibility of finding a wheat variety giving good yields of quality grain seems the most attractive option. As reported elsewhere, the project has established variety trials with this in mind. Several species of annual succulents ("espalaq") and some perennial small shrubs are reportedly invaded by sunnpest before they move into the wheat crop. Investigation should be carried out into whether these plants could be cultivated as a "trap crop". Such a crop could be used to concentrate the sunnpest in areas where they might be more easily controlled, and may also prove valuable in monitoring sunnpest; refuge crops that attract sunnpest have reportedly been used in Iran (FAO, 1958).

It has been suggested that barley could be substituted for wheat, since barley is not affected by sunnpest. This option is not considered practical due to consumer resistance to bread made from barley. Barley is considered a fodder crop. 


\title{
OTHER PEST PROBLEMS
}

\begin{abstract}
A9.1 Wheat DISEASES
Rusts, bunts and smuts can be serious problems in northern wheat-growing areas during wet years. Control is based on the use of resistant varieties, clean seed, crop rotation and fungicidal treatment. Traditional wheat varieties will almost certainly show acceptable levels of tolerance to most diseases, and therefore the careful monitoring of the disease tolerance of any newly-introduced varieties is essential. For seed dressing protestants, a mixture of carboxin and thiram (Vitavax 200) has been successfully used elsewhere in Afghanistan, and its introduction to northern wheat-growing areas through a series of farmer-managed demonstrations sponsored by the project would almost certainly be worthwhile. Hand-driven seed dressing drums could easily be manufactured locally: they carry a drum fixed on a stand which can be rotated or turned upside down by means of a handle; small iron plates are fixed internally at right angles to the surface of the drum and ensure the thorough mixing of seed with the chemical; alternatively, wire netting can be fixed horizontally inside the drum for the same purpose. The drums used for this purpose usually vary from 10 to $50 \mathrm{~kg}$ in capacity, and thus can treat from 200 to $700 \mathrm{~kg}$ of seed/day. Discussion between farmer community leaders and PPQD staff suggest that farmers are aware of the value of seed treatment, and that they would be willing to purchase both simple seed dressing machines, as described above, and seed dressing fungicide. This activity should be initiated as soon as possible.
\end{abstract}

\section{A9.2 ALMONDS}

Almonds are an important irrigated crop in Balkh and Samangan, and, as elsewhere in Afghanistan, serious pest problems can occur. Preliminary observations suggest, however, that these may differ significantly from the pests in southern areas. In particular, it would seem that the black-veined white butterfly - a key pest in southern orchards - is not a problem in northern Afghanistan. While control recommendations currently in use in IPM demonstrations under project AFG/92/008 would provide a basis for control, it is necessary, through pest survey activities, to more clearly define the key pest problems affecting the crop.

\section{A9.3 GRAPES}

Grapes are widely cultivated in irrigated land throughout the project area. Powdery mildew is generally accepted as being the key pest problem; although this appears not to be so in an area of about 1200 ha in Samangan Province, centred around Makshir, where partial trellising is practised. It is interesting to speculate that the reduced importance of powdery mildew results from improved air movement and exposure to sunlight caused by the vines 
being trellised rather than grown over large earth mounds; some demonstrations of trellising in areas where powdery mildew is serious should be established.

The project is currently undertaking a demonstration of powdery mildew control in grape-growing areas in Herat Province, and this control should be expanded into other grapegrowing areas during 1995. These activities should be supported by surveying aimed at obtaining a fuller understanding of pest pröblems in the crop. Farmer understanding needs to be expanded through training programmes. Again, technical guidelines for grape pest management demonstrations currently being undertaken by AFG/92/008 should be consulted (Watt, 1994).

\section{A9.4 Pomegranates}

Pomegranates are an important crop in northern Afghanistan and problems with fruit splitting apparently cause serious losses. The cause of this condition, as well as other pest problems in the crop, needs urgent clarification, and this should be given priority in any future activities under the ICP project.

\section{A9.5 Melons}

Various types of melons are extensively cultivated both under irrigation and in rotation with dryland wheat. Serious pest problems have been noted including:

- $\quad$ rodents eating newly-planted seed and damaging ripening fruit;

- locusts and grasshoppers feeding on and killing young plants (up to 100\% crop loss was observed in dryland areas of Herat Province in 1994);

damage to ripening fruit, initially thought to be by fruit fly.

Locust control is considered in detail elsewhere. The problems of rodent damage to various crops in Afghanistan is obviously serious. Control will never be simple. Zinc phosphide has been used in Afghanistan in the past, including substantial quantities sent cross-border by NGOs since 1987. Baiting around the margins of fields may provide adequate protection, and an anticoagulant rodenticide, such as brodifacoum, would probably be more effective than zinc phosphide.

Nor will fruit fly control be simple. The first step would be to identify the species involved. Both the melon fruit fly, Dacus cucurbitae, and the Balochistan melon fly, Myropardalis pardalina, are recorded as serious pests in Afghanistan. If any fruit fly pest species is involved, every attempt should be made to import supplies of male attractants and traps that could be used both as a means of determining the onset of attack and as an extension tool to convince farmers of the relationship between adult flies caught in the traps and larvae damaging fruit. Agrisense BCS Ltd (UK) should be able to supply both male attractants and traps, as well as protein hydrolysate (q.v). Actual control must be based on the collection and destruction of infested fruit, and will almost certainly need to be supplemented by pesticide application. This could be in the form of regular sprays of pesticide, such as dimethoate or fenitrothion, designed to control emerging larvae: this will not prevent egg laying, and thus fruit distortion may still occur, particularly with water melons. Alternatively, if application can be organized on a community basis so that most vines in an area can be treated, an insecticide, such as malathion, combined with an 
attractant, such as protein hydrolysate, could be used to attract and kill female flies. It would obviously be necessary to verify the control strategies described above through farmer-based demonstrations conducted over at least two seasons, before any attempt could be made to give firm recommendations to farmers.

\section{A9.6 Potatoes}

As with pomegranates, pest problems in potatoes have been frequently brought to the notice of the project. Potato tuber moth is an identified problem, and control demonstrations, incorporating cultural and chemical control, would be technically straightforward. Other problems are less well understood. A number of pests and diseases are known to occur in Afghanistan, and some are certainly seriously affecting both yields and quality in the project area. Again, there is an immediate need for pest survey activities aimed at identifying and quantifying these problems.

\section{A9.7 WEEDS AND BIRDS}

The above information represents a preliminary discussion of a few major pest problems in the project area, and there is no doubt that others of equal importance will become evident during future project implementation. No mention has been made of bird or weed problems in wheat, both of which are clearly important. Apart from suggesting the use of a combination of as many visual and auditory scaring methods as possible, little can be proposed for bird control. On the basis of experience gained in Africa, traditional bird scaring methods can be ineffective and time consuming, although they can be improved to increase their effectiveness and reduce labour input. A bird scarer sitting on the top of a wooden platform can periodically jerk a network of strings, stretching from the centre of the platform and covering all the crop area, to which various types and sizes of empty cans and bottles are attached. The purpose is to create different levels and types of noise, likely to confuse the birds and drive them away, rather than cracking whips, rattling cans, or shouting and throwing stones (to which the birds quickly adapt). The scaring can be integrated with the positioning of blue and orange flags (not white or any other colour), shown to be repulsive to attacking birds. Also scarecrows, in the form of men with raised arms or looking as if they are running in the field to scare birds, possibly made in such a way that they move with the occasional movement of the wind, would - in combination with improved scaring and flagging - significantly increase the efficiency of the control operation and reduce the time used by farmers in scaring birds.

Weed problems in wheat and other crops include grasses, such as wild oats, sedges and a wide range of broadleaves. Parasitic plants, including dodder, affecting vegetables and field crops are widely distributed. Management of these problems is complex and will involve accurate identification of problem weeds, followed by the development of integrated control strategies: cultural control methods (land preparation, crop rotation, use of clean seed, hand weeding, mulching, irrigation etc.) combined with, in selected cases, chemical intervention. Current problems in the project area may be aggravated by the extensive areas of land being brought back into cultivation, shortage of farm power and labour and possibly, ill-advised use of herbicides. There is clearly an immediate need for precise technical clarification of the problems involved and for the development and demonstration of 
appropriate integrated control strategies; these activities would probably need to be assisted by expert consultancy services. 


\section{CHEMICAL CONTAINER SPECIFICATIONS FOR USE IN FARMER-BASED CONTROL OPERATIONS}

\section{A10.1 Transportation of chemicals to Afghanistan}

Containers should conform to the following criteria:

- 5-litre capacity;

- $\quad$ Dari warning labels to be applied by supplier (project to supply translations);

- $\quad$ PET containers.

Pallets not to be stacked one on top of the other during transportation.

\section{A10.2 SPECIAL PROCUREMENT RECOMMENDATIONS FOR CHEMICAL AND SPRAYERS}

1) Each consignment is to arrive with sufficient extra empty containers to allow for chemical in damaged containers to be decanted. As a guide, it is recommended that sufficient extra containers be provided, with warning labels attached, to allow for $5 \%$ of the consignment to be decanted if necessary.

2) WFP shipping instructions are to be followed. Note that for shipping containers it is a one-way trip to Afghanistan. WFP guidelines are to be followed.

3) - Safety equipment (gloves and protective overalls) is to be ordered and supplied with each consignment of sprayers and chemicals. At present, safety equipment is ordered separately, which results in insufficient 'gear being available or becoming separated from the chemicals.

- $\quad$ The equipment should be supplied by the chemical supplier and included in the delivery of chemicals. As a guide, one pair of gloves should be supplied for every 5 litres of chemical and one pair of protective overalls for every 40 litres of chemical.

- One pair of gloves and one pair of overalls should be supplied with every sprayer ordered.

- $\quad$ The supply of the safety equipment should be made the responsibility of the supplier of the chemical or sprayer.

- $\quad$ Nitrile gloves are recommended.

4) The attachment of Dari warning labels to all equipment and chemical containers should be made the responsibility of the supplier. The project will supply translations with Purchase Orders.

Note: It can take six months for consignments to arrive in Afghanistan after ordering. 


\section{BHC IN NORTHERN AFGHANISTAN}

BHC is classed as carcinogen by the WHO and is highly persistent in the environment. It is a bio-accumulator, i.e. it accumulates in the food chain rather than being passed out. In mammals it accumulates in fat. Its formulation is highly stable, i.e. the isomers which make up the benzene hexachloride molecule remain unchanged for long periods (tens of years) in the environment.

\section{A11.1 Results of GTZ ANALysis}

Samples were sent to the GTZ pesticide laboratories in Germany, and the results of the analysis are set out below:

\section{Sample 1. Miamana, Faryab Province}

Content declared: $\quad$ BHC dust

Content analysed: $\quad 10.3 \% \mathrm{BHC}$ isomers

Sample 2 and sample 4. Shiberghan, Jozjan Province

Content declared: $\quad$ BHC dust

Content analysed: $\quad 11.8 \% \mathrm{BHC}$ isomers and

$11.3 \%$ BHC isomers

\section{Sample 3. Mazar-e-sharif, Balkh Province}

Content declared: $\quad$ BHC dust

Content analysed: $\quad 16.2 \% \mathrm{BHC}$ isomers

According to the GTZ report: the ratio of the various isomers of $\mathrm{BHC}$ is identical for all the samples taken and is typical for technical $\mathrm{BHC}$; the formulation of between 10 and $15 \%$ is common for BHC dust. 


\section{FIELD DOCUMENTS}

Dobson, H., 1994. Report on information consultancy for FAO Project, Field Crop Protection in Northern Afghanistan.

FAO Project Manual. Field crop protection training manual.

Patterson, M. and N. Akbari, 1995. Plant protection in Faryab - a socio-economic assessment. Oxfam/FAO.

Watt, M., June 1994. Field Crop Protection in Northern Afghanistan - consultants report.

Watt M., Dec. 1994. Sunnpest and training - consultants report. 


\section{REFERENCES}

Ali, S., 1985. The fall of a sparrow Delhi. Oxford University Press. 265 pp.

Allan, 1979. Tribe and village agrosystems of the Hindu Kush. PhD Thesis, Scaracuse University".

Brown, E.S., 1960. Notes on the systematic and distribution of some species of Aelia Fabr. (Hemiptera, Pentatomoidea) in the Middle East, with special reference to therostrate group. Ann. Mag. Nat. Hist. Ser. 13: 129-45 pp.

Brown, E.S., 1962. Research on the biology and ecology of Eurygaster integriceps (Puton) (Hemiptera: Scutelleridea in Middle Eastern countries, with special reference to the overwintering period. Bull. Ent. Res. 53(3): 445-514 pp.

Brown, E.S. and M. Eralp, 1962. The distribution of species of Eurygaster Lap. (Hemiptera: Scutelleridae) in Middle Eastern countries. Ann. Mag. Nat. Hist. 13: 65-81 pp.

Cejehan, A., 1969. Bertrage zurkenninis der. fauna Afghanistan Acridoidea. Orth. Cas. Morav. Mus. Berne (Sei. Nat). 44 (Supp.): 229-276 pp.

Chandra, H. and C. Singh, 1981. Some lizard predators of acridids of south western Afghanistan. Plant Protection Bull. India. 33 (3/4): 153-55 pp.

COPR, 1982. The locust and grasshopper agriculture manual. Centre for Overseas Pest Research, London. 690 pp.

Cotterell, G.S., 1953. Major pest of crops in Afghanistan; a preliminary note. Plant Protection Bull. FAO. 1: 52-55 pp.

Dobson, H., 1991a. Report on visit to Afghanistan 27 Feb. - 14 April 1991. Rome, FAO $\mathrm{UNO} / \mathrm{AFG} / 009 / \mathrm{UN}$.

Dobson, H., 1991b. Report on visit to Afghanistan 3-25 Nov 1991. Rome, FAO. $\mathrm{UNO} / \mathrm{AFG} / 009 / \mathrm{UNA}$.

Dobson, H.N., 1993. Visit to Islamabad to provide technical support to the FAO locust and sunn pest project, UNO/AFG/013/UNA. Islamabad, FAO. 33 pp.

Donskoff, M., 1966. Sunn pest control. Report to the Government of Afghanistan. UNDP Report No. 2190. Rome. FAO. 10 pp. 
Dudley, E., 1993. The critical village. Loncion and 1/O.L. Routledge. 173 pp.

Edwards, C.R. and J.L. Rann, 1990. Afghanistan. Locust and Sunn pest control project. Islamabad SAID/REP. 40 pp. plus appendixes.

FAO, 1970. Plant pest disease situation in the region, Near East Regional Office. 13 pp.

FAO, 1971. List of plant pests and diseases of economic importance in Afghanistan. Cairo, FAO Near East Regional Office. 32 pp.

FAO, 1981. Plant collection and herbarium development. FAO Plant Production and Protection Paper No.33. Rome. FAO.

FAO, 1990. ULV Locust and Sunn pest control Mazar-i-Sharif. FAO Locust and Sunn pest Project.

FAO, 1990. Evaluation of field trial data on the effectiveness of insecticide to locusts and grasshoppers. Report of the Pesticide Referee Panel. Nov. 1990. Rome, FAO. 14 pp.

FAO, 1992. The desert locust guidelines: (iii) information and forecasting; (iv) control; (v) campaign organization. Rome, FAO.

FAO, 1992. The desert locust guidelines: (ii) survey. Rome, FAO.

FAO, 1993. Report of the expert consultation on Sunn pest problem and its control in the Near East Region. Aleppo, 16-20 May 1993, Cairo. FAO Regional Office for the Near East. 28 pp.

Fedotov, D.M. (ed.), 1947-60. The noxious pentatomid, (Puton). Vols i-iv. Moscow. Akad. Nawk. USSR. 1070 pp.(in Russian).

Gentry, J.W., 1965. Crop insects of northern Africa - southwest Asia. Hand. Agric. Res. Serv. US. No. 273: $210 \mathrm{pp}$.

GIFAP, 1988. Guidelines for the safe warehousing of pesticides. Brussels. GIFAP. 68 pp.

Granovsky, T.A. et al., 1992. Training program for pesticide users. Trainers Manual. Peshawar. DAI/USAID (in Persian).

Greathead, D.J. (ed.), 1976. A review of biological control in western and southern Europe. Tech. Commn. Commonw. IIBC. No.7. 182 pp.

Gruys, P., 1992. Project TCP/AFG/2251. Support to Agriculture Rehabilitation Programmes. Mission Report. 15 Sept. - 21 Nov. 1992. Islamabad, FAO.

Harvey, 1992. Outbreak of new sunn pest in Afghanistan. FAO Plant Prot. Bull. Vol. 40/4. 
Hussaini, S.H., 1993. Country status report on the sunn pest problem in Afghanistan. FAO/ICARDA Expert Consultation on Sunn pest control in the Near East, 16-20 May 1993, A6 ppo. 10 pp.

Jago, N.D., 1963. A revision of the genus Callitamus Serville (Orthoptera: Acrididae). Bull. Br. Mus. Nat. Hist. (Ent). 13: 289-350 pp.

Javahery, M., 1993. Sunn pest (Pentatomoidea) of cereal crops in Iran: chemical and cultural methods of control. FAO/ICARA Expert consultation on Sunn pest, Aleppo, 1993. $16 \mathrm{pp}$.

Khan, M.A., 1964. Research and control of sunn pest, (Eurygaster integriceps Puton) in USSR. Food and Agriculture Council. $26 \mathrm{pp}$.

Lal, S.B., 1993. Plant Diseases in Afghanistan. Publication No. 2, Plant Protection Association of Afghanistan. $37 \mathrm{pp}$.

Latchininsky, A.V. and M.H. Launois-Luong, 1992. Le criquet marocain Dociostaurus maroccanus (Thunberg, 1815) dans la partie orientale de son aire de distribution Montpellier. CIRADAT-GERDAT-PRIFAS/St Petersburg. VIZR. 270 pp (in French).

Me Nutt, D.N., 1976. Insect collection in the tropics. London, Centre for Overseas Pest Research. 68 pp.

Merton, L.F.H., 1961. The Moroccan locust (Dociostaurus maroccanus (Thunberg)) in Iran. London. Anti-Locust Research Centre. Anti-locust Bulletin 37. 66 pp.

Mischenco, L.L., 1952. Insects, Orthopera. Vol. IV, No. 2. Asrididae (Ctantopinae) Fauna SSSR No.54: 610 pp. (in Russian; English Translation Israel Programme for Scientific Translation, Jerusalem, PST cat. No. 833, 1965).

Pastre, P. et al., 1989. Locust and grasshopper control Deltamethrin File. Paris Rousell Uelaf. $127 \mathrm{pp}$.

Paludan, K., 1959. On the birds of Afghanistan. Vidensk. Medd. Dansk, naturh. For. 122: $1-322 \mathrm{pp}$.

Rann, J., 1991. Afghanistan. Locust and Sunn pest Control Project. Final report and evaluation. USAID/DAI. 20 pp. plus attachments.

Remaudiere, G., 1959. Sunn pest in the Near East and Mediterranean countries. Report to the Governments of Afghanistan, Iran, Lebanon, Turkey and the United Arab Republic. EPTA Report No. 1225. Rome, FAO. 16 pp.

Remaudiere, G., 1961. Afghanistan, Iran, Lebanon and the United Arab Republic; Sunn pest investigation in 1960. Report to the Governments. EPTA Report No. 1392. Rome, FAO $21 \mathrm{pp}$. 
Roberts, T.J., 1991. The Birds of Pakistan. Vol.1. Karachi. Oxford University Press. 59 pp.

SCA, 1990a. Seventh report, Agricultural Survey of Afghanistan. Northern Afghanistan Crop Protection Programme Peshawar. Swedish Committee for Afghanistan. 51 pp.

SCA, 1990b. Eighth report, Agricultural Survey of Afghanistan. Northern Afghanistan Insect Samahe Survey. Peshawar. Swedish Committee for Afghanistan. 18 pp. IUS tables.

SCA, 1992. Fourteenth report, Agricultural Survey of Afghanistan. Swedish Committee for Afghanistan. 1991 Survey, June 1992.

Siddiqi, Z.A., 1973. Crop pests in Afghanistan. Publication No.1, Plant Protection Assoc. Afghanistan. Kabul. 36 pp.

Shamonine, M.G., 1964. The Moroccan locust and the desert locust in Afghanistan. First degree thesis, VIZR. Leningrad. 19 pp. (in Russian).

Shumakov, E.M., 1963. Acridoidae of Afghanistan and Iran. Trudy vses. ent. Obshch. 49: 3-248 pp. (in Russian).

Sondbo, S.D., 1992. The locust problem in Afghanistan and experiments with low-dosage spraying. The Agricultural University of Norway, as Cand. Agric. Thesis. $61 \mathrm{pp}$.

Sondbo, S. and P. Ottesen, 1991. Bird observations, Badakshan, Afghanistan NWFP, Pakistan. The Sandgrouse. $32 \mathrm{pp}$.

Stolyarov, M.V., 1971. Acriudoidea of the tribe Calliptamini (Orthoptera, Acrididae: Catontopinaea) in Afghanistan. Nauch Dok vyssh. Biol. Nauki SSSR 14: 16-22 pp. (in Russian).

Talhouk, A.M.S., 1969. Insects and mites injurious to crop in Middle Eastern countries. Monogrn angew. Ent. No. 12: 1-239 pp.

Tokgaiev, T., 1984. The economically important Acridoidea of Northern Afghanistan. Isvestiya. Akademii Nauk Turkmenshoi USSR. Seriya Biologitcheskih Nauk (3): 5556 pp. (in Russian).

USAID, 1992. Safe use of pesticides. Peshawar. ASSP/USAID. Publication No. 3 (in Pushto).

Uvarov, B., 1977. Grasshoppers and locust. Vol. 2. London Centre for Overseas Pest Research. 613 pp.

Watt, M.J., 1993. Preparatory assistance to ayricultural rehabilitation Afghanistan. Plant Protection. AFG/92/008. Field Document. Islamabad, FAO. 
Watt, M.J., 1994a. Desert locust training in Southern Afghanistan. UNO/AFG/021/UNA. Field Document. Quetta, FAO. $30 \mathrm{pp}$.

Watt, M.J., 1994b. Support for agricultural rehabilitation in Southern and Eastern Afghanistan. Plant Protection. AFG/92/008. Field Document. Islamabad, FAO.

Zillmsky, F.J., 1983. Common diseases of small grain cereals: a guide to identification. Mexico. CIMMYT. 141 pp.

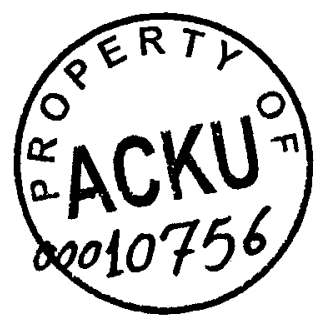

